R.Selvapriya, J.Mayandi, V.Ragavendran, V.Sasirekha,J.Vinodhini, J.M.Pearce. Dual Morphology Titanium Dioxide for Dye Sensitized Solar Cells. Ceramics International 45(6),7268-7277 (2019). https://doi.org/10.1016/j.ceramint.2019.01.008

\title{
Dual Morphologies of Titanium Dioxide for Dye Sensitized Solar Cells
}

\section{R. Selvapriya, J. Mayandi ${ }^{b}$ V. Ragavendran ${ }^{b}$, V. Sasirekha ${ }^{a^{*}}$, J. Vinodhini ${ }^{a}$, J. M. Pearce $^{\mathrm{c}, \mathrm{d}}$}

a Department of Physics, Avinashilingam Institute for Home Science and Higher Education for Women, Coimbatore, India.

${ }^{\mathrm{b}}$ Department of Materials Science, School of Chemistry, Madurai Kamaraj University, Madurai, India.

${ }^{c}$ Department of Materials Science \& Engineering and Department of Electrical \& Computer Engineering, Michigan Technological University, Houghton, MI 49931, USA.

d Department of Electronics and Nanoengineering, School of Electrical Engineering, Aalto University, Espoo, Finland.

*Corresponding author: saserekha@gmail.com

\section{ABSTRACT}

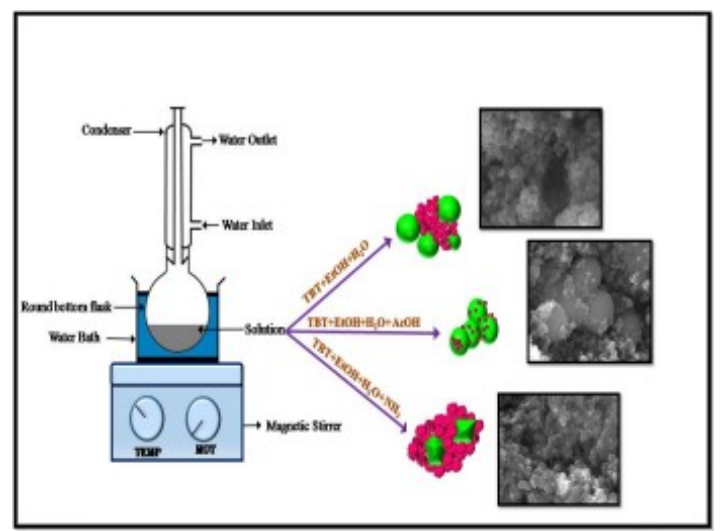

Anatase $\mathrm{TiO} 2$ displaying dual morphologies were synthesized with a simple chemical route via a single step. A strong correlation between the dye sensitized solar cell (DSSC) device performance and the obtained dual morphologies are highlighted using relevant evidences from UV-vis and diffuse reflectance spectroscopy (DRS), Raman analysis, field emission scanning electron microscope, high resolution transmission electron microscope, current-voltage characteristics and impedance analysis. Structural investigation revealed that the interested medium in this work employed for the synthesis of TiO2 produced different types of dual morphologies such as nanospheres with nanoparticles (NSNP), microsphere decorated with nanoparticles ( $\mu$ SNP) and nanoparticles with stone like features (NPS). UVvis and DRS results indicated the ability of the materials to assist with diffused reflectance and optical absorption of the screen printed photoanodes. In addition, an investigation of Raman vibrational characteristics was carried out in detail using synchronous and asynchronous 2D correlation analysis. The high intense Eg anatase mode of Raman spectrum was simulated using a phonon confinement model and its normalised spectra are compared with an experimental data. The resultant performances in the DSSCs were not indicative by the material properties; so, the charge transfer resistance (Rct) and recombination properties of the photoanode were investigated. These results showed that the Nyquist plot of NSNP possesses the smallest diameter, which reveals that the device based on NSNP offers the lowest Rct value that accounts for the higher conversion efficiencies when compared with the DSSC device based on photoanodes $\mu$ SNP and NSP. It can be concluded that the improved power conversion efficiency shown by photoanode fabricated using NSNP has the dual role of optimum surface area for dye loading and light scattering centres. These properties, when optimized along with the offered pathway for electrolyte diffusion to the dye degeneration with less Rct, could lead to better photoelectric conversion efficiency. 
R.Selvapriya, J.Mayandi, V.Ragavendran, V.Sasirekha,J.Vinodhini, J.M.Pearce. Dual Morphology Titanium Dioxide for Dye Sensitized Solar Cells. Ceramics International 45(6),7268-7277 (2019). https://doi.org/10.1016/j.ceramint.2019.01.008

\section{Key words:}

Composites, Screen Printing, 2D correlation, Phonon confinement, Dye Sensitized Solar Cell

\section{Introduction}

Grätzel and co-workers invented the dye sensitized solar cell (DSSC) with titanium dioxide (TiO2) nanostructure-based photoanodes. A conversion efficiency of $7.1 \%$ was reported with $\mathrm{TiO} 2$ colloidal solution coated fluorine-doped tin oxide (FTO) substrate with ruthenium $(\mathrm{Ru})$ sensitizer [1]. This seminal work created a significant interest in the research community because of the potential for low-cost solar cell production, an easy manufacturing process, and promising power conversion efficiency [2], [3], [4]. Tremendous efforts have been invested by various research groups to improve the photon to electron conversion efficiency of DSSC [5], [6], [7], [8]. Photovoltaic performance of the DSSC system depends on several parameters including the absorption range of the sensitizer, molar absorption coefficient, high performance electrolyte for the regeneration of dye, sheet resistance of the conducting transparent substrates and photochemically stable semiconductor materials [9], [10], [11], [12].

Much current research has been devoted to improving in the efficiency of DSSC by replacing standard Ru dyes with organic dyes, and developing photoanodes with various metal oxide semiconductors such as zinc oxide ( $\mathrm{ZnO})$, TiO2 and tin oxide (SnO2) [13], [14], [15], [16], [17]. Among these, titanium dioxide is one the most investigated photo anode material for DSSCs, because of its high chemical and thermal stability, low cost, high refractive index and favourable conduction band edges for efficient electron injection to many sensitizers [12], [18], [19]. The photovoltaic performance of the DSSC's strongly depends on the physical and structural properties of TiO2, including crystal size, morphology, phase composition, porosity, thickness of $\mathrm{TiO} 2$ layer, specific surface area in order to achieve strong light scattering capacity, dye loading ability, electron hole pair separation efficiency, electron transport and diffusion of electrolyte [20], [21], [22], [23].

The first DSSC device was assembled with TiO2 nanoparticles, which have the advantage of large surface area for efficient dye loading, but are suboptimal because of random electron path ways and dead ends that hamper electron transport [24]. The development of one dimensional (1-D) nanostructures such as nanorods [25] nanowires [26] and nanotubes [27] have been proven to provide superior directional pathways for the electrons to reach the conductive substrates as compared to nanoparticles. These 1-D nanostructures reduce the number of dead ends for electron transport [28]. 1-D nanostructures, however have some drawbacks including reduced dye loading [29], [30]. Thus, fully three dimensional (3-D) structures with different granules have been reported in an attempt to overcome these limitations in one dimensional and zero dimensional structures of TiO2 based DSSC [31].

Recent works have focused on developing dual nanostructures that combine two different morphologies like nanospheres and nanoparticles, nanorods with nanoparticles [32], [33]. Dual morphologies have shown promising synergism over the individual morphology based photoanodes and better performance with reference to bilayer working electrodes of compact layers over scattering layers [34], [35]. The compact layer formed by small sizes of nanoparticles has a higher surface area which provides a greater number of sensitizer molecules anchoring locations resulting in greater absorption and potential for photoelectron conversion [36]. Even though scattering layers offer better light scattering abilities, they can also result in decreasing surface area, which is a cause of interfacial charge transfer resistance [37]. 
The potential benefits of the use of dual morphology nanomaterials are that the optimum surface area can be tuned for efficient dye loading while the nanomaterials can also be tuned to provide optimal light scattering. In addition, the dual role of dual morphological nanomaterials support for better electron mobility and diffusion of electrolyte can improve performance of DSSC [38]. Dual morphology nanomaterials have been represented in some previously reported articles as nanocomposites [32], [39]. Liang et al. employed hydrothermal method to prepare anatase $\mathrm{TiO} 2$ microspheres with interconnected nanoparticles, which offered a photovoltaic conversion efficiency of $7.13 \%$ at an optimum thickness of $14.5 \mu \mathrm{m}$ [40]. Ilayaraja et al. synthesized $\mathrm{TiO} 2$ microspheres and higher conversion efficiency of $8.94 \%$ was achieved using dual morphology composite based photoanode by mixing 80 weight percentage of TiO2 synthesized microsphere and 20 weight percentage of P25 powder. This 80/20 mixed composite structure provides a higher surface area for better dye loading, and the interconnected sphere and particle nature helps in efficient electron transport, which results in better light harvesting capacity [32].

To build on that work, in this study, TiO2 dual morphologies including nanospheres with nanoparticles, microsphere decorated with nanoparticles and nanoparticles with stone like structures were prepared by a simple and one step reflux method. To the best of our knowledge, the projected synthesis mechanism is easy and less time-consuming when compared to already reported methodologies for the preparation of nanocomposites [40]. This work makes a significant contribution to the composite structure based $\mathrm{TiO} 2$ photoanode performance towards the incident photon to electron conversion efficiency.

\section{Experimental section}

\subsection{Materials and methods}

The following chemicals were used to synthesize and fabricate $\mathrm{TiO} 2$ composites without any further purification. Titanium (IV) butoxide (TBT, 97\% purity), ethanol AR (99.9\%), acetic acid (AcOH, 99-100\%), ammonia solution (25\%, Merck), double distilled water, titanium tetrachloride (99.5\%, Loba chemie), N719 - dye (Sigma), fluorine-doped tin oxide coated glass plate ( F-doped $\mathrm{SnO} 2: 13 \Omega / \mathrm{sq}$, sigma), chloroplatinic acid solution $8 \mathrm{wt} \%$ in H2O (Sigma Aldrich), 4-tert-butylpyridine, iodide (I2), lithium iodide (LiI).

\subsection{Synthesis of $\mathrm{TiO}_{2}$ composites}

$150 \mathrm{ml}$ of ethanol was taken in a round bottomed flask. $0.12 \mathrm{M}$ of titanium butoxide was dissolved under continuous stirring and refluxed at $80^{\circ} \mathrm{C} .90 \mathrm{ml}$ of water was added into the above solution. The experimental condition was maintained for $1 \mathrm{~h}$ and marked as NSNP. The same procedure was followed as for the sample, with an addition of required amount of acetic acid (pH-4.5) ammonia (pH-9), respectively named as sample $\mu$ PNP and sample NPS. The precipitate was filtered and washed with ethanol and dried at $80^{\circ} \mathrm{C}$. The obtained powders were calcinated at $470{ }^{\circ} \mathrm{C}$ for $1 \mathrm{~h}$ using a muffle furnace.

\subsection{Preparation of photoanodes}

A screen printable paste was prepared by mixing the annealed $\mathrm{TiO} 2$ powders as described in Section 2.2 with glycerol using an agate mortar and pestle. Prior to the deposition, FTO glass substrate was washed with Triton-X 100, followed by distilled water and acetone using an ultrasonic bath. The conductive side of the FTO substrate was pre- 
R.Selvapriya, J.Mayandi, V.Ragavendran, V.Sasirekha,J.Vinodhini, J.M.Pearce. Dual Morphology Titanium Dioxide for Dye Sensitized Solar Cells. Ceramics International 45(6),7268-7277 (2019). https://doi.org/10.1016/j.ceramint.2019.01.008

treated with $90 \mathrm{mM}$ TiCl4 solution at $70^{\circ} \mathrm{C}$ for $30 \mathrm{~min}$. Pre-treatment was followed by sintering at $450{ }^{\circ} \mathrm{C}$ for $30 \mathrm{~min}$ in an air atmosphere. The TiO2 paste was coated on the TiCl4 treated FTO substrate $(0.5 \mathrm{~cm} \times 0.5 \mathrm{~cm})$ using the screen printing method (AT-45PA). Subsequently, the coated films were annealed at $450^{\circ} \mathrm{C}$ for $30 \mathrm{~min}$ using a muffle furnace. Post-TiCl4 treatment was performed by following the same procedure followed for the pre $\mathrm{TiCl} 4$ treatment. Sensitization was performed by soaking the photoanodes in an anhydrous ethanol solution containing $0.5 \mathrm{mM}$ N719 dye for sixteen hours in the dark at ambient temperature. Pt counter electrode was prepared by $1 \mathrm{mM}$ of $\mathrm{H} 2 \mathrm{PtCl} 6 \cdot 6 \mathrm{H} 2 \mathrm{O}$ solution in 2propanol over the conductive substrate of FTO by drop casting method, followed by annealing at $450{ }^{\circ} \mathrm{C}$ for $30 \mathrm{~min}$. DSSCs were assembled by clipping counter electrodes over the photoanodes. The space between the sandwiched electrodes was filled with a based liquid electrolyte containing $0.3 \mathrm{M}$ 4-tert-butylpyridine, $0.5 \mathrm{M}$ iodide, $0.05 \mathrm{M}$ lithium iodide in acetonitrile.

\subsection{Characterization}

In order to identify the phase and crystal size of prepared powder samples, crystallographic characterization was performed using Rigaku ultima IV X-ray diffractometer with $\mathrm{Cu}-\mathrm{K} \alpha$ radiation. Morphology and nanostructural details of the synthesized materials were analysed using field emission scanning electron microscopy (FESEM, TESCAN MIRA 3) and high resolution transmission electron microscopy (HRTEM, FEI-TECNAI T20 G2). A UV-vis-NIR spectrometer was employed to investigate the light scattering abilities and dye loading capacity of photoanodes. (JASCO V770 Japan). Raman spectra were recorded using micro Raman spectrometer with excitation wavelength of $633 \mathrm{~nm}$ using a He-Ne laser. The shift of Raman bands with respect to particle sizes was analysed using shidge 2D software developed by Noda [41]. The electron transfer and recombination properties of the fabricated DSSCs were investigated using electrochemical impedance spectra measurements with a CHI600 electrochemical analyzer. Photocurrent-voltage measurements of DSSCs were carried out using a Keithley 2400 source meter under one sun illumination (AM 1.5). I-V and electrochemical measurements were performed in an open cell configuration.

\section{Results and Discussion}

\subsection{Synthesis Mechanism}

The dual morphological nanostructures were obtained using a predefined general synthesis mechanism which is detailed as follows. The precursor of Ti source undergoes two important steps in the adopted synthesis mechanism of this present work. First, the process of hydrolysis takes place with the aid of a solvent and a hydrolysis agent of alcohol water system. During hydrolysis, the Ti precursor forms a Ti-OH network by replacing its butoxide groups. The second process of condensation occurred between Ti-OH-OH-Ti networks, as they form a non hydrolytic network of Ti-O-Ti from the hydrolytic occurred during the previous process [42], [43]. The precipitation of $\mathrm{TiO} 2$ occurring at the end of the whole process is represented in the schematic diagram of Fig. 1.

There is intensive research on the synthesis of monodispersed mesoporous $\mathrm{TiO} 2$ spheres having the range of $100 \mathrm{~nm}$ to $12 \mu \mathrm{m}$ based on the hydrolysis and condensation reaction pathway. This had been achieved in the medium of solvent and hydrolysing agent. Here the deciding factor for hierarchical morphology is the molar ratio between the Ti source and hydrolysizing agent. Ethanol/water is the most commonly chosen solvent and hydrolysing system and the most comprehensive analysis on this subject was carried out by 
Hong et al. [44]. In order to obtain a uniform size distribution the formation nuclei should occur simultaneously in a short period of time. The growth rate and concentration of growth species should also be rapid in order to avoid further nucleation [45]. The formation of dual morphology nanomaterials in this present work can be obtained either from the slow growth rate (allowing more nucleation sites to form during the growth process) or when the concentration of growth species is less (which also allows for secondary nucleation to occur) [45]. In the formation of spheres with nanoparticles combination, the nuclei for the sphere shaped nanoparticles may be formed initially and further growth takes place over an extended time period. The process of growth is in such a way that it leaves precursors at a high enough concentration to create further nucleation and therefore both the processes could have happened simultaneously. Finally in the chosen environmental condition with precursor/hydrolysing solvent molar ratio nanospheres with nanoparticles mixtures was achieved. The addition of acetic acid in the water/ethanol system may speed up the process of growth rate or may help in aggregation of primarily nucleation sites in the shape of microspheres with the granules of nanoparticles. As it has acted as forward catalyst to increase the growth rate/aggregation of nucleation sites, further formation of nucleation sites are significantly reduced. In this way nanoparticles are formed on the surface of grown microspheres.

A higher number of primary/secondary nucleation sites occurs and the smaller aggregation results in florets of cauliflower-top-surface-like structures with irregular shaped nanoparticles formed in the presence of ammonia. Larger aggregation resulted in stone like structures. The evolutions of morphologies are given as the schematic diagram of Fig. 2.

\subsection{X-ray diffraction analysis}

X-ray diffraction analysis was carried out to identify phase formation and the crystallographic structure of the prepared samples. Fig. 3. shows the X-ray diffractograms of the synthesized powders. The X-ray diffraction peaks located at $2 \theta$ values of $25.3^{\circ}, 38.6^{\circ}$, $48.1^{\circ}, 53.9^{\circ}, 55.1^{\circ}, 62.8^{\circ}, 68.8^{\circ}, 70.4^{\circ}$, and $75.2^{\circ}$ can be attributed to (101), (004), (200), (105), (211), (204), (116), (220) and (215) planes of the tetragonal structure of anatase phase $\mathrm{TiO} 2$ with I41/amd space group symmetry (JCPDS Card No. 894921). No other peaks corresponding to secondary phases were detectable in the XRD pattern indicating the formation of pure anatase phase of synthesized samples. The sharp and intense reflection at (110) plane reveals the strong crystalline nature of the material, which may be favourable for electron transport. The lattice parameters a and c for all the synthesized $\mathrm{TiO} 2$ samples are determined corresponding to the tetragonal structure using the following expression [46]:

$$
\frac{1}{d^{2}}=\frac{h^{2}+k^{2}}{a^{2}}+\frac{l^{2}}{c^{2}}
$$

The calculated and standard d values with respect to their hkl planes for NSNP are given in Table 1. The standard and calculated lattice parameters for all materials are listed in Table 2.

Crystal sizes were calculated from the broadening of most intense (101) reflection using Debye Scherer's formula for all the samples [47]. The calculated crystalline sizes were found to be $12.21 \mathrm{~nm}, 12.95 \mathrm{~nm}$, and $16.10 \mathrm{~nm}$ for NSNP, $\mu$ SNP, NSP respectively indicating that the addition of acetic acid and ammonia both results in increase in crystal size, which decreases the full width half maxima of the diffraction peaks. 
R.Selvapriya, J.Mayandi, V.Ragavendran, V.Sasirekha,J.Vinodhini, J.M.Pearce. Dual Morphology Titanium Dioxide for Dye Sensitized Solar Cells. Ceramics International 45(6),7268-7277 (2019). https://doi.org/10.1016/j.ceramint.2019.01.008

\subsection{Scanning electron microscopy analysis}

The morphological features of prepared $\mathrm{TiO} 2$ powders were examined using field emission scanning electron microscopy. Fig. 4. (a-c) presents the FESEM image of TiO2 composites and (d-f) particle size distribution curves of corresponding FESEM images. Fig. 4. clearly indicates that addition of acetic acid and ammonia plays a significant role in morphological changes. Fig. 4(a) shows FESEM images of synthesized TiO2 powders in water/ethanol binary solvent system. This dual morphology nanostructure consists of a proportion of spheres and nanoparticles which are well interconnected to each other. Spheres are in the average range of $170 \mathrm{~nm}$ in diameter. Fig. 4(b) represents the micrograph image of the sample on addition of acetic acid. It consists of microspheres. These microspheres have smooth surfaces and are composed of nanoparticles granules. These smooth surface microspheres are naturally well diffused to each other neck to neck among the growth species. Nanoparticles are decorated over the surfaces of these microspheres. As ammonia was used in addition to the binary solvent system of ethanol with water, the morphology of the sphere was affected greatly which was evident from Fig. 4(c) which resulted in another morphology due to the larger aggregation of nanoparticles. These stone like morphologies had smooth surfaces. The smaller aggregation of nanoparticles resulted in florets of cauliflower like structures of the order of less than $50 \mathrm{~nm}$.

\subsection{Transmission electron microscopy analysis}

The structure and crystallinity of anatase $\mathrm{TiO} 2$ were further investigated by high resolution transmission electron microscopy along with corresponding selected area electron diffraction pattern. Fig. 5(a) shows the HRTEM morphology of the synthesized NSNP TiO2 powder. It confirms the presence of morphological features that are spherical shaped. Fig. 5(b) shows the SAED pattern of TiO2 powder as spotty sharp ring pattern. The sharp ring pattern in selected area diffraction confirms the prepared $\mathrm{TiO} 2$ are crystalline in nature. The lattice space values are calculated from diffraction rings of SAED pattern, the calculated lattice space values are $0.35 \mathrm{~nm}, 0.24 \mathrm{~nm}, 0.19 \mathrm{~nm}, 0.17 \mathrm{~nm}, 0.15 \mathrm{~nm}$ indexed to (101), (004), (200), (105) and (204) planes of anatase phase TiO2. The SAED pattern analysis is in agreement with XRD measurements.

\subsection{Laser Raman studies and phonon confinement model}

Laser Raman spectroscopy has been employed to confirm the anatase phase $\mathrm{TiO}_{2}$. The anatase phase belongs to the $\mathrm{D}^{19}{ }_{4 \mathrm{~h}}$ space group with two formulas per unit cell. Based on group theory the anatase $\mathrm{TiO}_{2}$ consists of one $A_{1 \mathrm{~g}}$, two $\mathrm{B}_{1 \mathrm{~g}}$, and three $\mathrm{E}_{\mathrm{g}}$ modes as shown in Fig. 6. The Raman lines centred at $145 \mathrm{~cm}^{-1}, 197 \mathrm{~cm}^{-1}, 399 \mathrm{~cm}^{-1}, 518 \mathrm{~cm}^{-1}$, and $639 \mathrm{~cm}^{-1}$ are attributed due to $E_{g}, E_{g}, B_{1 g}, A_{1 g},+B_{1 g}$, $E_{g}$, modes of anatase respectively [48]. Fig. 7 depicts normalized experimental Raman spectra of $144 \mathrm{~cm}^{-1}$ mode.

The phonon confinement model (PCM) correlates the Raman scattering peak position and shape with size distribution effect of $\mathrm{TiO} 2$ nanocrystals. When the phonons are confined in the case of small sized crystals contraction of translational symmetry occurs. Due to this the phonon wave function is expressed as a Gaussian confinement function instead of plane wave. The attention is focussed on the high intense Eg Raman active mode for the phonon confinement model. In the case of spherical nanocrystalline materials the Raman band intensity is proportional to the superposition of weighted Lorentizan contribution over the Brillion zone represented in the Eq. (2). 
$I() \alpha \sum_{i=1}^{2} \int \frac{e^{\left(\frac{-q^{2} L^{2}}{2 \alpha}\right)}}{\left(-\square_{i}(q)\right)^{2}+\left(\frac{\Gamma_{0}}{2}\right)^{2}} d^{3} q \rightarrow()$

Where

$$
\begin{aligned}
& \square_{1}(q)=\square_{0}+\square_{1}(1-\cos (q \cdot a)) \rightarrow() \\
& \square_{2}(q)=\square_{0}+\square_{2}(1-\cos (q \cdot a)) \rightarrow()
\end{aligned}
$$

Here $\square_{0}=143 \mathrm{~cm}^{-1} \square_{1}=28 \mathrm{~cm}^{-1} \square_{2}=102 \mathrm{~cm}^{-1}[37] . \Gamma_{0}$ is the FWHM of the $143 \mathrm{~cm}^{-1}$ Raman peak for bulk anatase which is $7 \mathrm{~cm}^{-1}$. $\mathrm{q}$ and a are the wave vector and lattice constant. The theoretical simulation was performed using simple phonon dispersion using representation given in equation (2) and (3) for the characteristics peak of anatase $143 \mathrm{~cm}^{-1}$

Fig. 8. shows normalized simulated Raman spectra for different crystal sizes 12.21 $\mathrm{nm}, 12.95 \mathrm{~nm}$ and $16.10 \mathrm{~nm}$ calculated using Eqs. (2), (3), (4). The calculated Raman spectra using PCM provides evidence for the systematic shift towards the higher wave number side and a broadening of the FWHM with respect to a decrease in the nano crystallite size. It also agreed with an experimental observation given in Fig. 7. PCM reflects the influence of crystallite dimension on the lattice dynamics modification because PCM takes into account the contributions of phonons even away from the zone centre which result the shape variation in Raman line.

\subsection{Two dimensional correlation analysis:}

In order to perform an analysis of the shift of Raman band position with respect to particle size, the samples were analysed using two dimensional correlation spectroscopy. Fig. 9 shows (a) synchronous and (b) asynchronous 2-D correlation spectra in the spectral range of $90-190 \mathrm{~cm}^{-1}$ from the experiemental Raman spectra. The synchronous spectrum develops a single autopeak at $145 \mathrm{~cm}^{-1}$, while the corresponding asynchronous spectrum exhibits the standard butterfly pattern, which consists of a pair of cross peaks with opposite sign located at 143 and $148 \mathrm{~cm}^{-1}$, repsectively. The 1-D Raman spectra and 2-D synchronous spectrum divulge a single peak at $145 \mathrm{~cm}^{-1}$ whereas the corresponding asynchronous spectrum has two cross peaks at $143 \mathrm{~cm}^{-1}$ and $148 \mathrm{~cm}^{-1}$, which indicates the shifting of band position. The direction of shift is determined by the sign of the peaks in the asynchronous spectrum. In Fig. 10b the cross peak above the diagonal line is positive and below the diagonal line is negative, which indicates the band position is shifting from higher a wavenumber side to lower wave number side [50].

Fig. 9 (c,d) shows the synchronous and asynchronous 2-D correlation spectra in the region of $300-700 \mathrm{~cm}^{-1}$. The synchronous counter map develops three auto peaks at 640,516 , $397 \mathrm{~cm}^{-1}$. While asynchronous cross peaks located at 637,514,396 $\mathrm{cm}^{-1}$. The presence of three auto peaks represents the intensity variation occurs at different wave numbers. In addition to that the synchronous spectrum has positive cross peaks at $(640,516) \mathrm{cm}^{-1},(640,397) \mathrm{cm}^{-1}$, and $(516,399) \mathrm{cm}^{-1}$ indicating that a decrease in intensity in the pair of bands occurs in same direction. The observation from synchronous and asynchronous 2-D correlation analysis indicates that all the above indicated peaks are shifted to the lower wave number side as a function of increasing particle size [51]. 


\subsection{UV-Vis spectra analysis}

The light scattering abilities of photoanodes plays a critical role in the efficiency enhancement of DSSC. Scattering occurs, when the electromagnetic radiation meets the particles whose sizes are comparable to the wavelength of the light. Photons are scattered either in a diffused form or in the specular form. The DSSC takes advantage of diffused reflectance. The diffused reflectance increases the optical path length of the incident photon inside the medium of $\mathrm{TiO} 2$. After sensitization the $\mathrm{TiO} 2$ medium gets associated with the grafted sensitizer molecules. Hence the probability of interaction increases between the sensitizer molecules with photon which leads to an increase in photon absorption. Hence, the light scattering abilities of the screen printed photoanodes without dye loading can be recognized by UV-vis diffused reflectance spectra, which is a good indicator to the performance of the material in the PV device.

The NPS exhibited higher diffused reflectance for the entire visible region starting from 350 to $800 \mathrm{~nm}$. The differences between the DRS of the photoanodes screen printed by the NSNP, $\mu S N P$ with respect to NPS are clearly visible from the Fig. 10. Fig. 11 shows the UV-vis absorption spectra of photoanodes after dye sensitization process. Fig. 11 clearly indicates that NPS demonstrated the highest absorption among all the synthesized dual morphologies. All the samples comfortably agreed with the diffused reflectance measurement results. Superior performance of NSP among the three samples may be due to higher surface area for more dye loading and higher diffused scattering ability. Higher dye loading capability of the NPS is due to the higher density of smaller available nanoparticles in the NPS. Fig. 4(c) shows that small numbers of particles are more numerous. When compared to other two samples NPS also has a denser packing as seen in the FESEM micrographs. This is also further supported by the particle size distribution curves. In Fig. 4(b) diffused microsphere contents are more in proportion when compared to the nanoparticles proportions. Even though the NSNP has higher proportion of nanoparticles as compared to its constituent spherical morphology, the density of particle packing in the obtained structures may be less compared to NPS. Hence, the diffused reflectance and optical absorption strongly agreed with the above interpretation of the morphology content.

\section{8 .Photovoltaic performance of DSSCs}

Fig. 12a represents a schematic device configuration and working mechanism of dye the sensitized solar cell. The photons from the sunlight strikes the dye molecules anchored on semiconductor photoanode. The electrons excited by the energy of photon will be injected from the lowest unoccupied molecular orbital of sensitizer to the conduction band of $\mathrm{TiO}_{2}$ when the potential of conduction band matches with LUMO of sensitizer. Here the injected electron travels through the thickness of the $\mathrm{TiO}_{2}$ layer within its life time. These electrons reache the conductive substrate of FTO in the working electrode and from here go to the counter electrode through the load. Meanwhile regeneration of sensitizer should take place in order to maintain stability otherwise the whole system could not continue its operation by dye degradation. Here the redox mediator of $\mathrm{I}^{-} / \mathrm{I}_{3}$ couple supply electrons for the oxidised sensitizer to bring it to its neutral state. In this way the process again starts from the initial point in order to continue the DSSC cycle. 
The photovoltaic performance were analysed by measuring the current-voltage curves under one sun illumination. Fig. 12b shows the current density-voltage curves of three photoanodes and corresponding photovoltaic parameters are listed in Table 3.The photo anode A shows highest short circuit current density $\left(\mathrm{J}_{\mathrm{SC}}\right)$ of $11.48 \mathrm{~mA} / \mathrm{cm}^{2}$, open circuit voltage $\left(\mathrm{V}_{\mathrm{OC}}\right) 0.66 \mathrm{~V}$ and overall power conversion efficiency $4.17 \%$. Sample B and sample C exhibits the DSSC efficiency as $2.64 \%$ and 3.04\%, respectively. Sample B has a nature of the highest diffused light reflectance and more dye loading even though, it offers lower power conversion efficiency compared to sample A.

In general, the reported results agree with the UV-Vis diffused reflectance and absorption results. That is the highest diffused reflectance and the dominant absorption exhibited by the photoanodes had been shown higher efficiency in DSSC [52], but in the present investigation the obtained results of photovoltaic performance do not show the linear relationship with our UV-Vis diffused and absorption measurement. Hence, a more in-depth analysis of electron transport properties of photoanodes is provided below.

\subsection{Electrochemical Impedance analysis}

In order to investigate the charge transfer resistance and recombination properties of photo anodes electrochemical impedance spectra (EIS) measurements were carried out for the fabricated DSSC under dark condition. Fig. 13 (a) represents the Nyquist plots for three different photo anodes DSSCs. The impedance data of the DSSCs were fit by the equivalent circuit using ZView software and corresponding EIS parameters are summarized in Table 3. An equivalent circuit consisting of series resistance $\left(R_{S}\right)$, charge transfer resistance $\left(R_{c t}\right)$ and constant phase element (CPE) offer the best fit for impendence plots. Generally a semicircle with large radius of curvature in the Nyquist plot is ascribed to the electron transport phenomenon across the interface of $\mathrm{TiO}_{2}$ /dye/electrolyte. In addition to that it also accounts the electron transport within $\mathrm{TiO}_{2}$ layer. From Fig 13 (a) the Nyquist plot of sample A possess smallest diameter. It revels the device based on sample A offers the lowest Rct value when compared with the DSSC device based on photoanodes B and C. This lower charge transfer resistance of photoanode A could be attributed to the efficient charge transfer process and slower electron-hole recombination which leads to the best photovoltaic conversion efficiency. It may due to either it offers lower interface charge transfer resistance across working electrode/ Dye/ electrolyte interface or nanoparticles cum nanosphere structure may provide large number electron path ways for fast electron transport and diffusion of electrolyte.

Comparatively less photovoltaic performance of sample C with sample A may due to the huge number of trapping in the grain boundaries or lacking of enough diffusion of redox couple leads for higher $\mathrm{R}_{\mathrm{ct}}$, which restricts the power conversion efficiency of DSSC. Hence the electrochemical measurements strongly supported the results obtained from photovoltaic measurements results.

\section{Conclusions}

TiO2 dual morphology composite structures were successfully synthesized and demonstrated for use in DSSCs. Out of the three different dual morphologies prepared by a simple less time consuming procedure the material consisting of nanospheres with nanoparticles exhibited a higher solar conversion efficiency. Even though the dual morphology of nanoparticles with stone like structure exhibited higher scattering ability and more optical absorption it showed non linearity with power conversion performance in DSSC. This phenomenon is discussed with experimental evidence obtained from 
R.Selvapriya, J.Mayandi, V.Ragavendran, V.Sasirekha,J.Vinodhini, J.M.Pearce. Dual Morphology Titanium Dioxide for Dye Sensitized Solar Cells. Ceramics International 45(6),7268-7277 (2019). https://doi.org/10.1016/j.ceramint.2019.01.008

electrochemical impedance measurements. In conclusion the improved power conversion efficiency of nanospheres with nanoparticles have the dual role of providing optimum surface area for dye loading and acting as light scattering centres. These properties when optimized along with the offered pathway for electrolyte diffusion to the dye degeneration with less charge transfer resistance could lead to better photoelectric conversion efficiency.

\section{Acknowledgements}

We gratefully acknowledge the financial support and screen printing facility from Government of India, DST-SERB research grant under the project SR/FTP/PS-012/2011. The author JM is thankful to the UGC-UPE and DST-PURSE, MKU for the I-V measurements. JMP would like to thank the Richard Witte Endowment for Materials Science and Engineering for support of this work.

\section{References}

[1] B.O'Regan, M. Gratzel, A low-cost, high-efficiency solar cell based on dye sensitized colloidal $\mathrm{TiO}_{2}$ films, Nature 353 (1991) 737-740.

[2]M. Gratzel, Photoelectrochemical cells, Nature 414 (2001) 338-344.

[3] C.C. Liu, M.S. Liang, C.C. Khaw, Effect of gold nanoparticles on the performances of $\mathrm{TiO}_{2}$ dye-sensitised solar cell, Ceram. Int. 44(6) (2018) 5926-5931.

[4] P. Jayabal, V. Sasirekha, J. Mayandi, V. Ramakrishnan, Microwave assisted synthesis of zinc stannate nanocubes for dye sensitized solar cell application, Superlattices Microstruct. 75 (2014) 775-784.

[5] N. Sriharan, N.M. Ganesan, M. Kang, L. Kungumadevi, T.S. SenthilImproved photoelectrical performance of single crystalline rutile $\mathrm{TiO}_{2}$ nanorod arrays incorporating $\alpha$ alumina for high efficiency dye-sensitized solar cells

Mater. Lett., 237 (2019), pp. 204-208

[6] P. Selvaraj, A. Roy, H. Ullah, P. Sujatha Devi, A.A. Tahir, T.K. Mallick, S.

SundaramSoft template synthesis of high surface area mesoporous titanium dioxide for dye sensitized solar cells Int. J. Energy Res. (2018), pp. 1-12

[7] F. Xie, J. Wang, Y. Li, J. Dou, M. WeiOne-step synthesis of hierarchical $\mathrm{SnO}_{2} / \mathrm{TiO}_{2}$ composite hollow microspheres as an efficient scattering layer for dye-sensitized solar cells Electrochim. Acta, 296 (2019), pp. 142-148

[8] H.T. Chou, K.M. Lin, H.C. HsuFabrication of $\mathrm{TiO}_{2}$ compact layer precursor at various reaction times for dye sensitized solar cells Microelectron. Reliab., 55 (2005), pp. 2208-2212 
R.Selvapriya, J.Mayandi, V.Ragavendran, V.Sasirekha,J.Vinodhini, J.M.Pearce. Dual Morphology Titanium Dioxide for Dye Sensitized Solar Cells. Ceramics International 45(6),7268-7277 (2019). https://doi.org/10.1016/j.ceramint.2019.01.008

[9] S. Mathew, A. Yella, P. Gao, R.H. Baker, B.F.E. Curchod, N.A. Astani, I. Tavernelli, U. Rothlisberger, M.K. Nazeeruddin, M. GratzelDye-sensitized solar cells with $13 \%$ efficiency achieved through the molecular engineering of porphyrin sensitizers Nat. Chem., 6 (2014), pp. $242-247$

[10] Y. Hu, A. Abate, Y. Cao, A. Ivaturi, S.M. Zakeeruddin, M. Gratzel, N. RobertsonHigh absorption coefficient cyclopentadithiophene donor-free dyes for liquid and solid-state Dyesensitized solar cells J. Phys. Chem. C, 120 (2016), pp. 15027-15034

[11] I.P. Liu, W.N. Hung, H. Teng, S. Venkatesan, J.C. Lin, Y.L. LeeHigh- performance printable electrolytes for dye-sensitized solar cells J. Mater. Chem. A, 5 (2017), pp. 91909197

[12] G.S. Mital, M.T. ManojA review of TiO2 nanoparticles Chin. Sci. Bull., 56 (2011), pp. $1639-1657$

[13] Q. Huaulme, L. Cabau, R. DemadrilleAn important step toward more efficient and stable dye-sensitized solar cells Chem, 4 (2018), pp. 2260-2277

[14] M. Zi, M. Zhu, L. Chen, H. Wei, X. Yang, B. CaoZnO photoanodes with different morphologies grown by electrochemical deposition and their dye-sensitized solar cell properties Ceram. Int., 40 (2014), pp. 7965-7970

[15] L. Wei, P. Wang, Y. Yang, Z. Zhan, Y. Dong, W. Song, R. FanEnhanced performance of the dye-sensitized solar cells by the introduction of graphene oxide into the $\mathrm{TiO} 2$ photoanode Inorg. Chem. Front., 5 (2018), pp. 54-62

[16] R. Zan, J. Xiao, X. WenSynthesis of TiO2 nanorice and their improved dye sensitized solar cells performance J. Mater. Sci: Mater. Electron., 28 (2017), pp. 4107-4113

[17] A.E. Shalan, M. Rasly, I. Osama, M.M. Rashad, I.A. IbrahimPhotocurrent enhancement by $\mathrm{Ni2}+$ and $\mathrm{Zn} 2+$ ion doped in $\mathrm{SnO} 2$ nanoparticles in highly porous dye-sensitized solar cells Ceram. Int., 40 (2014), pp. 11619-11626

[18] M. Pelaez, N.T. Nolan, S.C. Pillai, M.K. Seery, P. Falaras, A.G. Kontos, P.S.M. Dunlop, J.W.J. Hamilton, J.A. Byrne, K. O'Shea, M.H. Entezari, D.D. DionysiouA review on the visible light active titanium dioxide photocatalysts for environmental applications Appl. Catal. B Environ., 125 (2012), pp. 331-349

[19] V.M. Ramakrishnan, M. Natarajan, A. Santhanam, V. Asokan, D. VelauthapillaiSize controlled synthesis of $\mathrm{TiO} 2$ nanoparticles by modified solvothermal method towards 
R.Selvapriya, J.Mayandi, V.Ragavendran, V.Sasirekha,J.Vinodhini, J.M.Pearce. Dual Morphology Titanium Dioxide for Dye Sensitized Solar Cells. Ceramics International 45(6),7268-7277 (2019). https://doi.org/10.1016/j.ceramint.2019.01.008

effective photo catalytic and photovoltaic applications Mater. Res. Bull., 97 (2018), pp. 351360

[20] Z.S. Wang, H. Kawauchi, T. Kashima, H. ArakawaSignificant influence of TiO2 photoelectrode morphology on the energy conversion efficiency of N719 dye-sensitized solar cell Coord. Chem. Rev., 248 (2004), pp. 1381-1389

[21] Y.K. Hwang, S.S. Park, J.H. Lim, Y.S. Won, S. HuhPreparation of anatase/rutile mixed-phase titania nanoparticles for dye-sensitized solar cells J. Nanosci. Nanotechnol., 13 (2013), pp. 2255-2261

[22] J.M.K.W. Kumari, N. Sanjeevadharshini, M.A.K.L. Dissanayake, G.K.R. Senadeera, C.A. ThotawatthageThe effect of $\mathrm{TiO} 2$ photoanode film thickness on photovoltaic properties of dye-sensitized solar cells Ceylon J. Sci., 45 (2016), pp. 33-41

[23] Z. Zhao, G. Liu, B. Li, L. Guo, C. Fei, Y. Wang, L. Lv, X. Liu, J. Tianab, G. CaoDyesensitized solar cells based on hierarchically structured porous $\mathrm{TiO} 2$ filled with nanoparticles J. Mater. Chem. A, 3 (2015), p. 11320

[24] P. Zhao, S. Yao, M. Wang, B. Wang, P. Sun, F. Liu, X. Liang, Y. Sun, G. LuHighefficiency dye-sensitized solar cells with hierarchical structures titanium dioxide to transfer photogenerated charge Electrochim. Acta, 170 (2015), pp. 276-283

[25] K.P. Ghoderao, S.N. Jamble, R.B. KaleInfluence of reaction temperature on hydrothermally grown $\mathrm{TiO} 2$ nanorods and their performance in dye-sensitized solar cells Superlattices Microstruct., 124 (2018), pp. 121-130

[26] B.R. Koo, H. An, H.J. AhnHigh-surface area co-electrospun TiO2 nanowires fabricated using shrinkage of polyvinylpyrrolidone for improved photovoltaic performance Ceram. Int. 42 (2016), pp. 1666-1671

[27] Z. Hou, W. Que, J. Ren, Y. Xing, H.M.A. Javed, T. Zhou, L.B. KongFabrication and stability of opened-end TiO2 nanotube arrays based dye-sensitized solar cells Ceram. Int., 41 (2015), pp. S719-S724

[28] J. Qu, C. LaiOne dimensional TiO2 nanostructures as photoanodes for dye sensitized solar Cells J. Nanomater. (2013) (Article ID762730 11)

[29] M.A. Gaikwad, A.A. Mane, S.P. Desai, A.V. MoholkarTemplate-free TiO2 photoanodes for dye-sensitized solar cell via modified chemical route J. Colloid Interface Sci., 488 (2017), pp. 269-276 
R.Selvapriya, J.Mayandi, V.Ragavendran, V.Sasirekha,J.Vinodhini, J.M.Pearce. Dual Morphology Titanium Dioxide for Dye Sensitized Solar Cells. Ceramics International 45(6),7268-7277 (2019). https://doi.org/10.1016/j.ceramint.2019.01.008

[30] L. Zhao, Y. Wang, S. Wang, B. Dong, L. WanAg nanoparticle-decorated 3D flower-like $\mathrm{TiO} 2$ hierarchical microstructures composed of ultrathin nanosheets and enhanced photoelectrical conversion properties in dye-sensitized solar cells J. Power Sources, 292 (2015), pp. 49-57

[31] L. Xu, J. Xu, H. Hu, C. Cui, Z. Ding, Y. Yan, P. Lin, P. WangHierarchical submicroflowers assembled from ultrathin anatase $\mathrm{TiO} 2$ nanosheets as light scattering centers in TiO2 photoanodes for dye-sensitized solar cells J. Alloy. Compd., 776 (2019), pp. 1002-1008

[32] P. Ilaiyaraja, T.K. Das, P.S.V. Mocherla, C. SudakarWell-connected microspherenanoparticulate $\mathrm{TiO} 2$ composites as high performance photoanode for dye sensitized solar cell Sol. Energy Mater. Sol. Cells, 169 (2017), pp. 86-97

[33] G. Rajamanickam, S. Narendhiran, S.P. Muthu, S. Mukhopadhyay, R. PerumalsamyHydrothermally derived nanoporous titanium dioxide nanorods/nanoparticles and their influence in dye-sensitized solar cell as a photoanode Chem. Phys. Lett., 689 (2017), pp. 19-25

[34] Z. Shen, G. Wang, H. Tian, J. Sunarso, L. Liu, J. Liu, S. LiuBi-layer photoanode films of hierarchical carbon-doped brookite-rutile $\mathrm{TiO} 2$ composite and anatase $\mathrm{TiO} 2$ beads for efficient dye-sensitized solar cells Electrochim. Acta, 216 (2016), pp. 429-437

[35] L. Zhu, Y.L. Zhao, X.P. Lin, X.Q. Gu, Y.H. QiangThe effect of light-scattering layer on the performance of dye-sensitized solar cell assembled using $\mathrm{TiO} 2$ double-layered films as photoanodes Superlattice Micro., 65 (2014), pp. 152-160

[36] H. Xu, X. Tao, D.T. Wang, Y.Z. Zheng, J.F. ChenEnhanced efficiency in dye-sensitized solar cells based on $\mathrm{TiO} 2$ nanocrystal/nanotube double-layered films Electrochim. Acta, 55 (2010), pp. 2280-2285

[37] M.B. Qadir, K.C. Sun, I.A. Sahito, A.A. Arbab, B.J. Choi, S.C. Yi, S.H. JeongComposite multi-functional over layer: a novel design to improve the photovoltaic performance of DSSC Sol. Energy Mater. Sol. Cells, 140 (2015), pp. 141-149

[38] Y.H. Sim, M.J. Yun, S.I. Cha, S.H. Seo, D.Y. LeeImprovement in energy conversion efficiency by modification of photon distribution within the photoanode of dye-sensitized solar cells. ACS Omega, 3 (2018), pp. 698-705

[39] N. Huang, F. Chen, P. Sun, X. Sun, B. Sebo, X. ZhaoA four-functional compositehierarchical anatase $\mathrm{TiO} 2$ microsphere consisting of nanoparticles, nanowires and submicron ellipsoidal spheres for dye sensitized solar cells Electrochim. Acta, 143 (2014), pp. 232-239 
R.Selvapriya, J.Mayandi, V.Ragavendran, V.Sasirekha,J.Vinodhini, J.M.Pearce. Dual Morphology Titanium Dioxide for Dye Sensitized Solar Cells. Ceramics International 45(6),7268-7277 (2019). https://doi.org/10.1016/j.ceramint.2019.01.008

[40] L. Chu, Z. Qin, Q. Zhang, W. Chen, J. Yang, J. Yang, X. LiMesoporous anatase TiO2 microspheres with interconnected nanoparticles delivering enhanced dye-loading and charge transport for efficient dye-sensitized solar cells Appl. Surf. Sci., 360 (2016), pp. 634-640

[41] I. NodaTwo dimensional infrared (2D IR) spectroscopy of synthetic and biopolymer Bull. Am. Phys. Soc., 31 (1986), p. 520

[42] T.Y. Kim, K. Alhooshani, A. Kabir, D.P. Fries, A. MalikHigh pH-resistant, surfacebonded sol-gel titania hybrid organic-inorganic coating for effective on-line hyphenation of capillary microextraction (in-tube solid-phase microextraction) with high-performance liquid chromatography J. Chromatogr. A, 1047 (2004), pp. 165-174

[43] A.B. Kashyout, M. Soliman, M. FathyEffect of preparation parameters on the properties of TiO2 nanoparticles for dye sensitized solar cells Renew. Energy, 35 (2010), pp. 2914-2920

[44] M.P. Hong, J.Y. Kim, K. Vemula, H.S. Kim, K.B. YoonSynthesis of monodisperse mesoporous $\mathrm{TiO} 2$ spheres with tunable sizes between 0.6 and $3.1 \mu \mathrm{m}$ and effects of reaction temperature, Ti source purity, and type of alkylamine on size and monodispersity Chem. Commun., 48 (2012), pp. 4250-4252

[45] G. Cao, Nanostructures and nanomaterials: synthesis, properties and applications ISBN 1-86094-415-9, 2004.

[46] P.B. Patil, S.S. Mali, V.V. Kondalkar, N.B. Pawar, K.V. Khot, C.K. Hong, P.S. Patil, P.N. BhosaleSingle step hydrothermal synthesis of hierarchical TiO2 microflowers with radially assembled nanorods for enhanced photovoltaic performance RSC Adv., 4 (2014), p. 47278

[47] N.D. Desai, S.S. Mali, R.M. Mane, V.B. Ghanwat, C.K. Hong, P.N. BhosaleInfluence of deposition temperature on the optical, structural, morphological, compositional and Photoelectrochemical properties of TiO2 thin films. J. Mater. Sci: Mater. Electron., 27 (2016), pp. 11739-11750

[48] G.D. Venkatasubbu, V. Ramakrishnan, V. Sasirekha, S. Ramasamy, J. KumarInfluence of particle size on the phonon confinement of TiO2 nanoparticles J. Exp. Nanosci., 9 (2014), pp. 661-668

[49] K.R. Zhu, M.S. Zhang, Q. Chen, Z. YinSize and phonon-confinement effects on lowfrequency Raman mode of anatase TiO2 nanocrystal Phys. Lett. A, 340 (2005), pp. 220-227

[50] M.A. CzarneckiInterpretation of two-dimensional correlation spectra: science or art? Appl. Spectrosc., 52 (1998), pp. 1583-1590 
R.Selvapriya, J.Mayandi, V.Ragavendran, V.Sasirekha,J.Vinodhini, J.M.Pearce. Dual Morphology Titanium Dioxide for Dye Sensitized Solar Cells. Ceramics International 45(6),7268-7277 (2019). https://doi.org/10.1016/j.ceramint.2019.01.008

[51] H.C. Choi, Y.M. Jung, S.B. KimCharacterization of Raman spectra of size-selected TiO2 nanoparticles by two-dimensional correlation spectroscopy Bull. Korean Chem. Soc., 25 (2004), pp. 426-428

[52] P. Zhang, Z. Hu, Y. Wang, Y. Qin, W. Li, J. WangThe effect of light-scattering layer on the performance of dye-sensitized solar cell assembled using $\mathrm{TiO} 2$ double-layered films as photoanodes Nano-Micro Lett., 8 (2016), pp. 232-239 


\section{Hydrolysis}

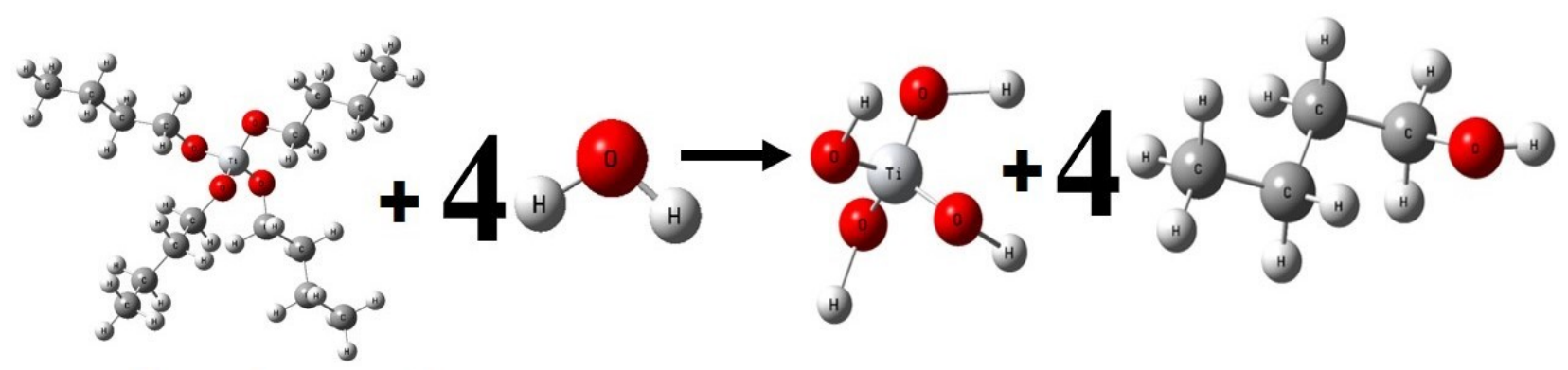

\section{Condensation}

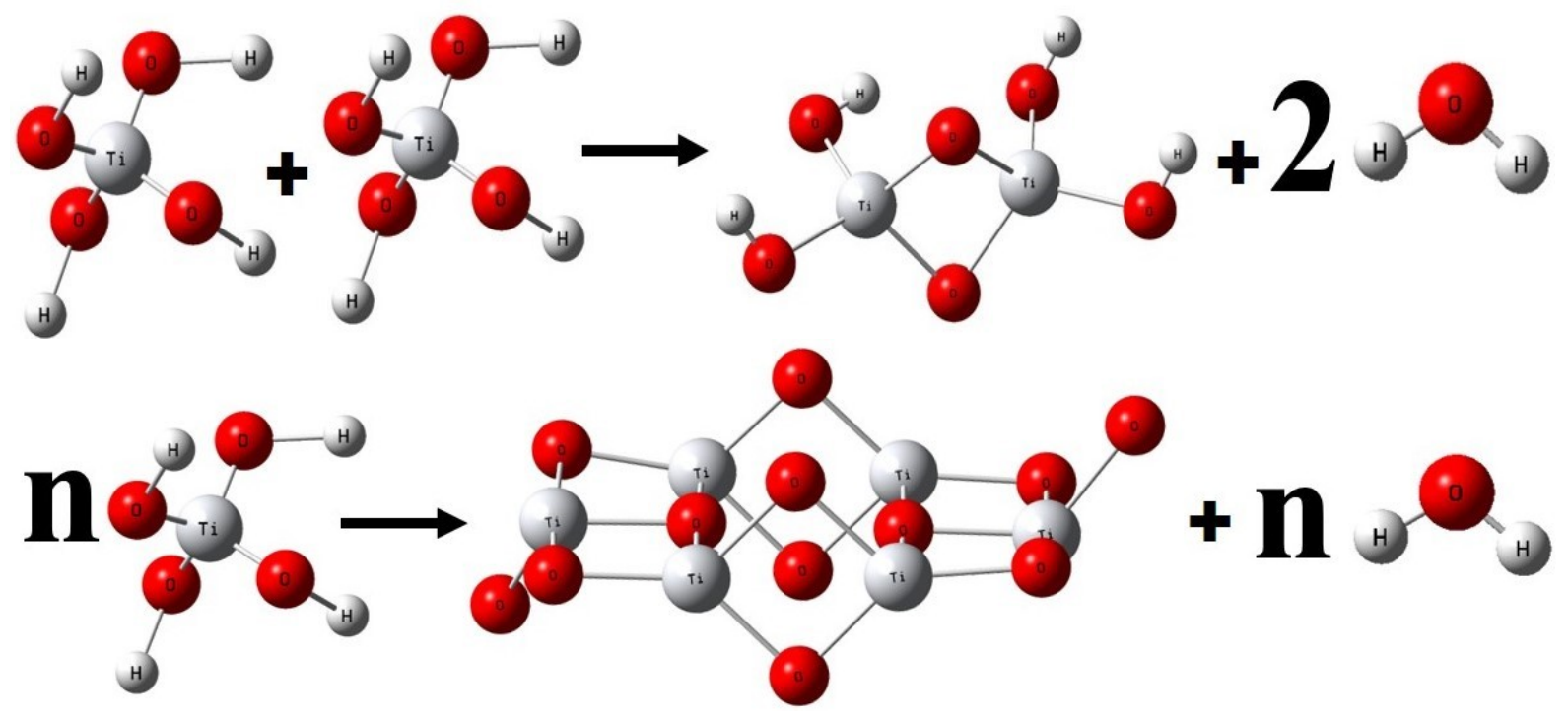

Fig. 1. Schematic diagram of hydrolysis and condensation reaction of $\mathrm{TiO}_{2}$ 


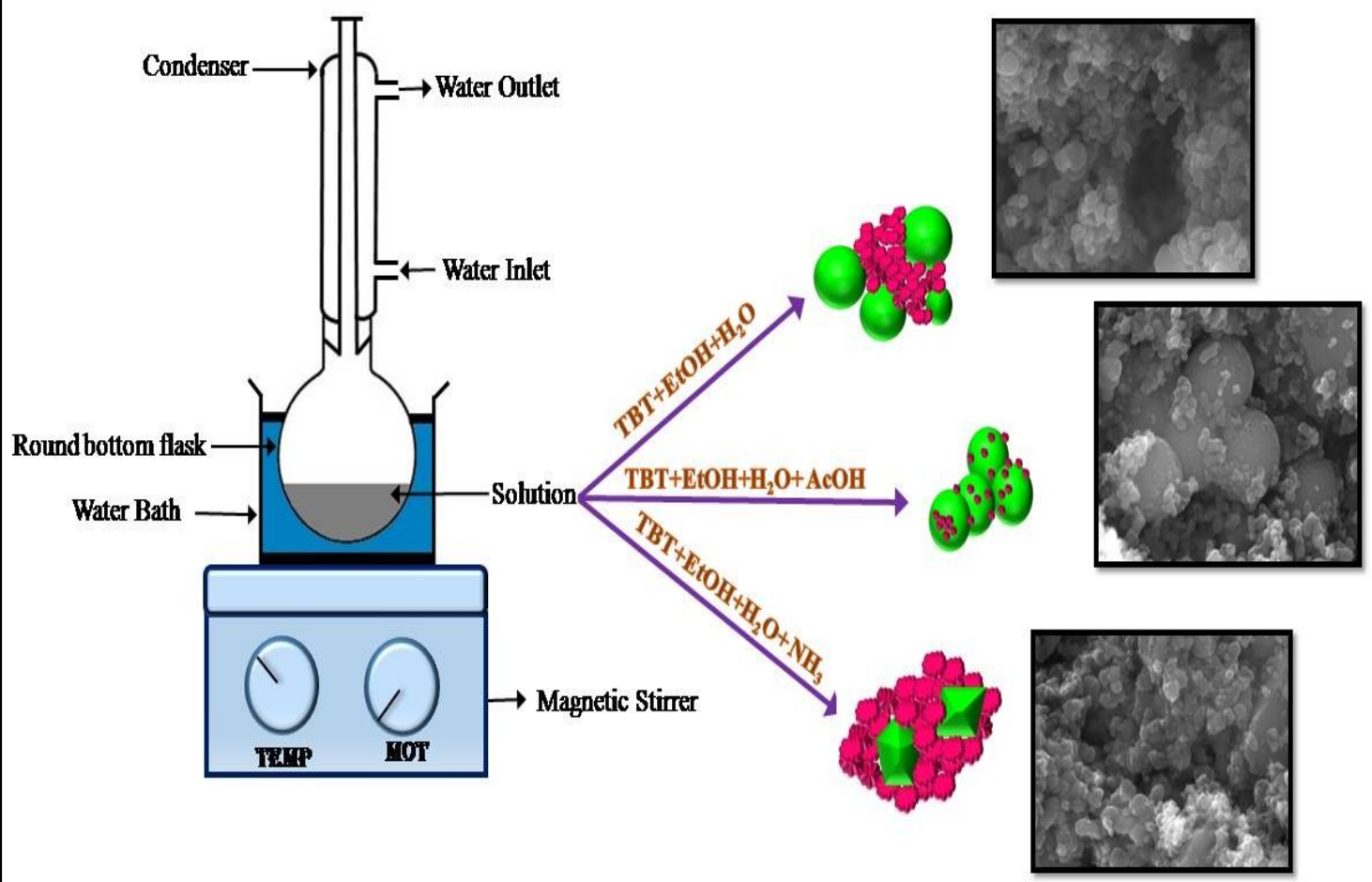

Fig. 2. Schematic diagram of evolution of nanocomposites.

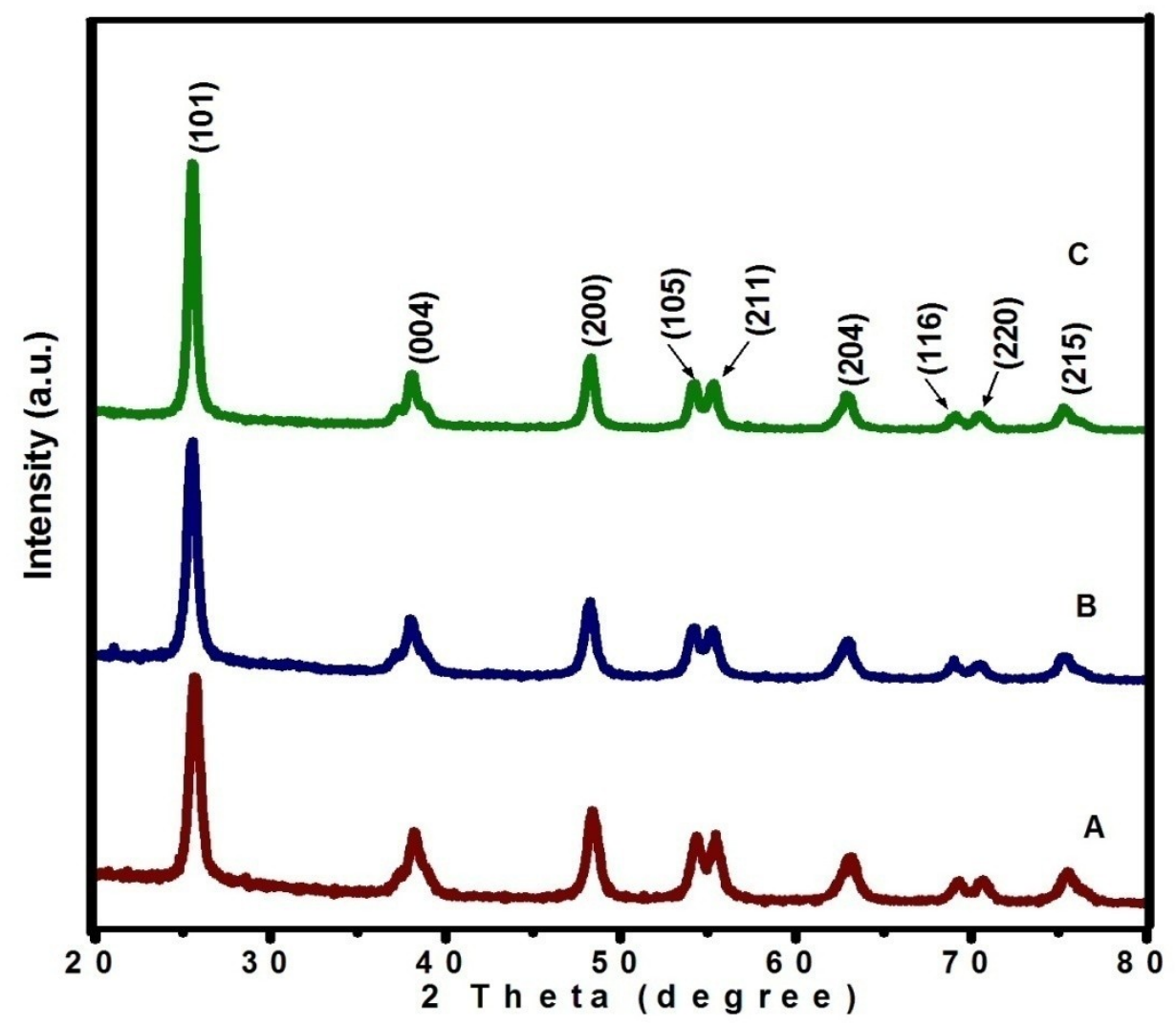


R.Selvapriya, J.Mayandi, V.Ragavendran, V.Sasirekha,J.Vinodhini, J.M.Pearce. Dual Morphology Titanium Dioxide for Dye Sensitized Solar Cells. Ceramics International 45(6),7268-7277 (2019). https://doi.org/10.1016/j.ceramint.2019.01.008

Fig. 3. The XRD pattern of prepared dual morphology $\mathrm{TiO}_{2}$ powders
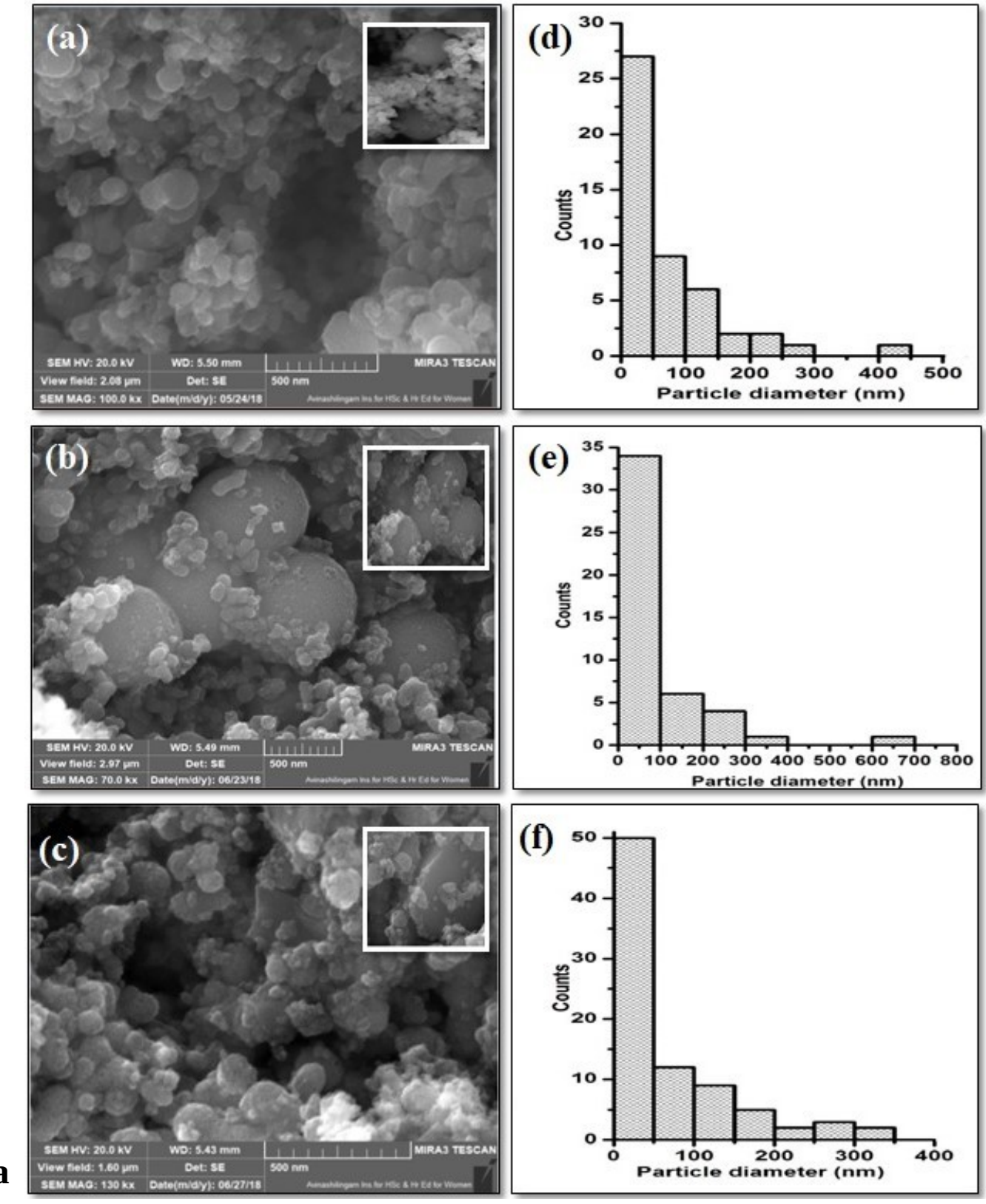

Fig. 4. FE-SEM images of the prepared dual morphology $\mathrm{TiO}_{2}$ materials (a) A (b) B and (c) C .(d-f) particle size distribtion curve from FE-SEM images. 
R.Selvapriya, J.Mayandi, V.Ragavendran, V.Sasirekha,J.Vinodhini, J.M.Pearce. Dual Morphology Titanium Dioxide for Dye Sensitized Solar Cells Ceramics International 45(6),7268-7277 (2019). https://doi.org/10.1016/j.ceramint.2019.01.008
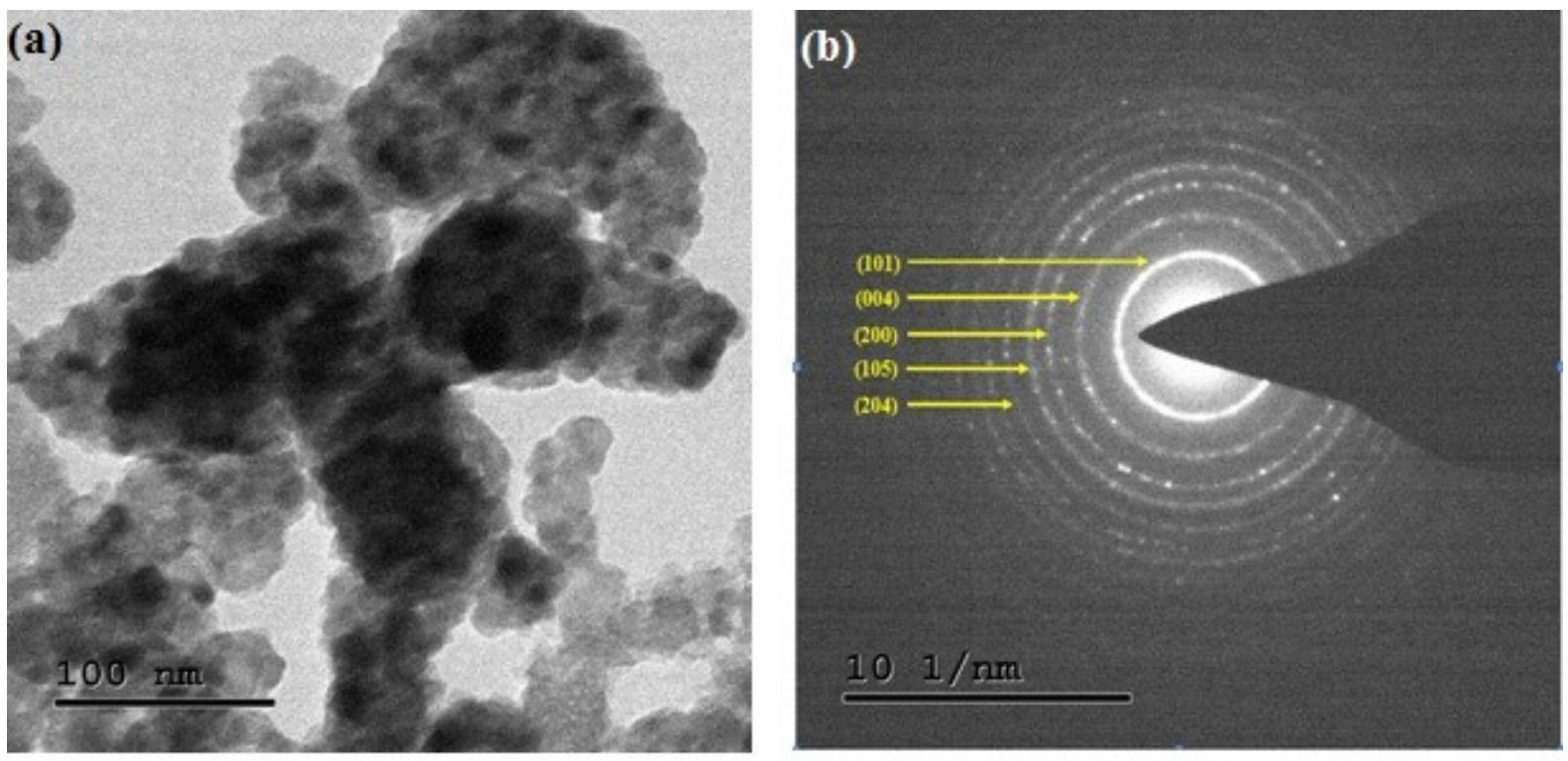

Fig. 5.(a) TEM micrograph of sample A (b) SAED pattern of $\mathrm{TiO}_{2}$. 


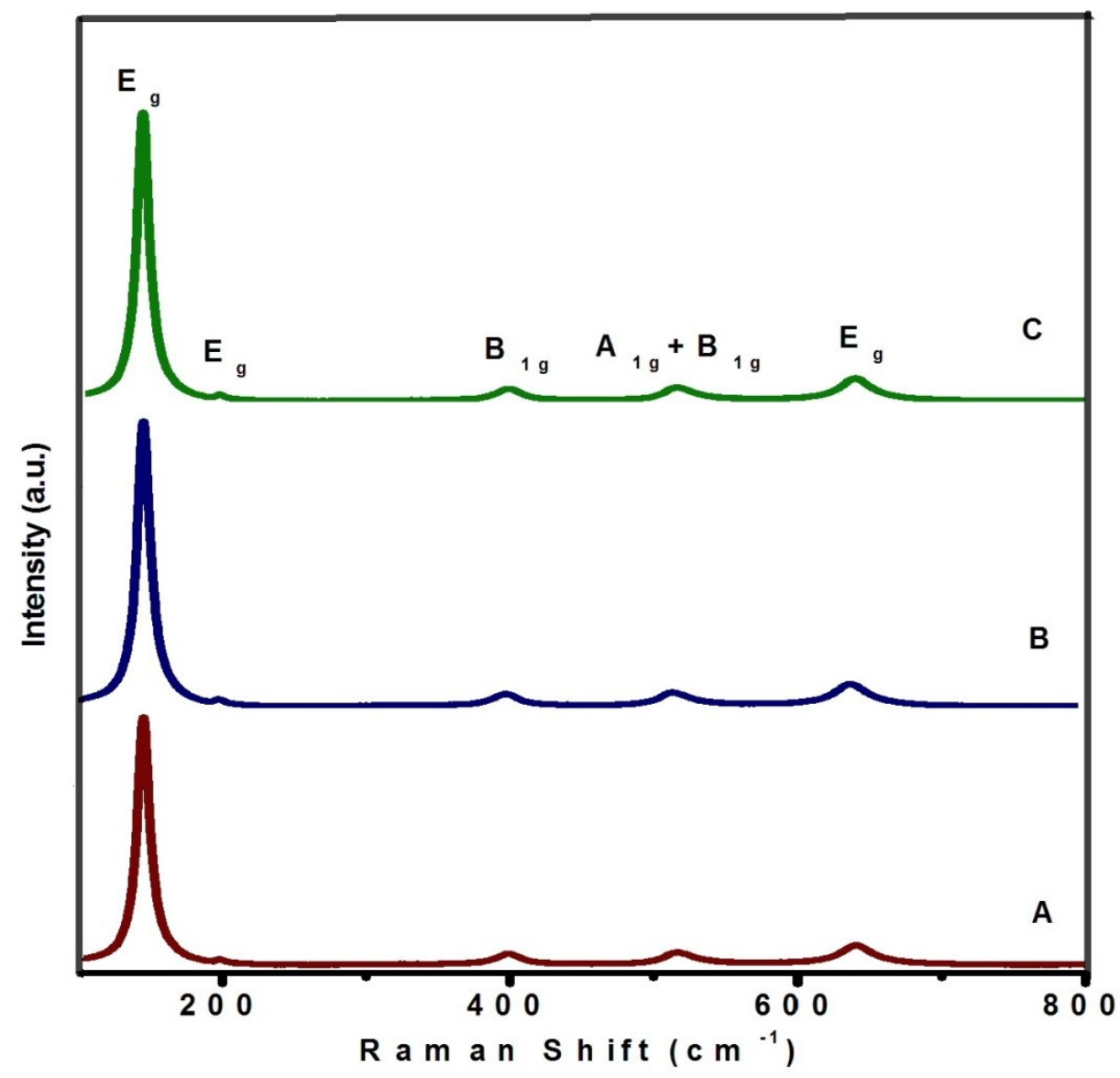

Fig. 6. Raman spectra of $\mathrm{TiO}_{2}$ powder samples 
R.Selvapriya, J.Mayandi, V.Ragavendran, V.Sasirekha,J.Vinodhini, J.M.Pearce. Dual Morphology Titanium Dioxide for Dye Sensitized Solar Cells. Ceramics International 45(6),7268-7277 (2019). https://doi.org/10.1016/j.ceramint.2019.01.008

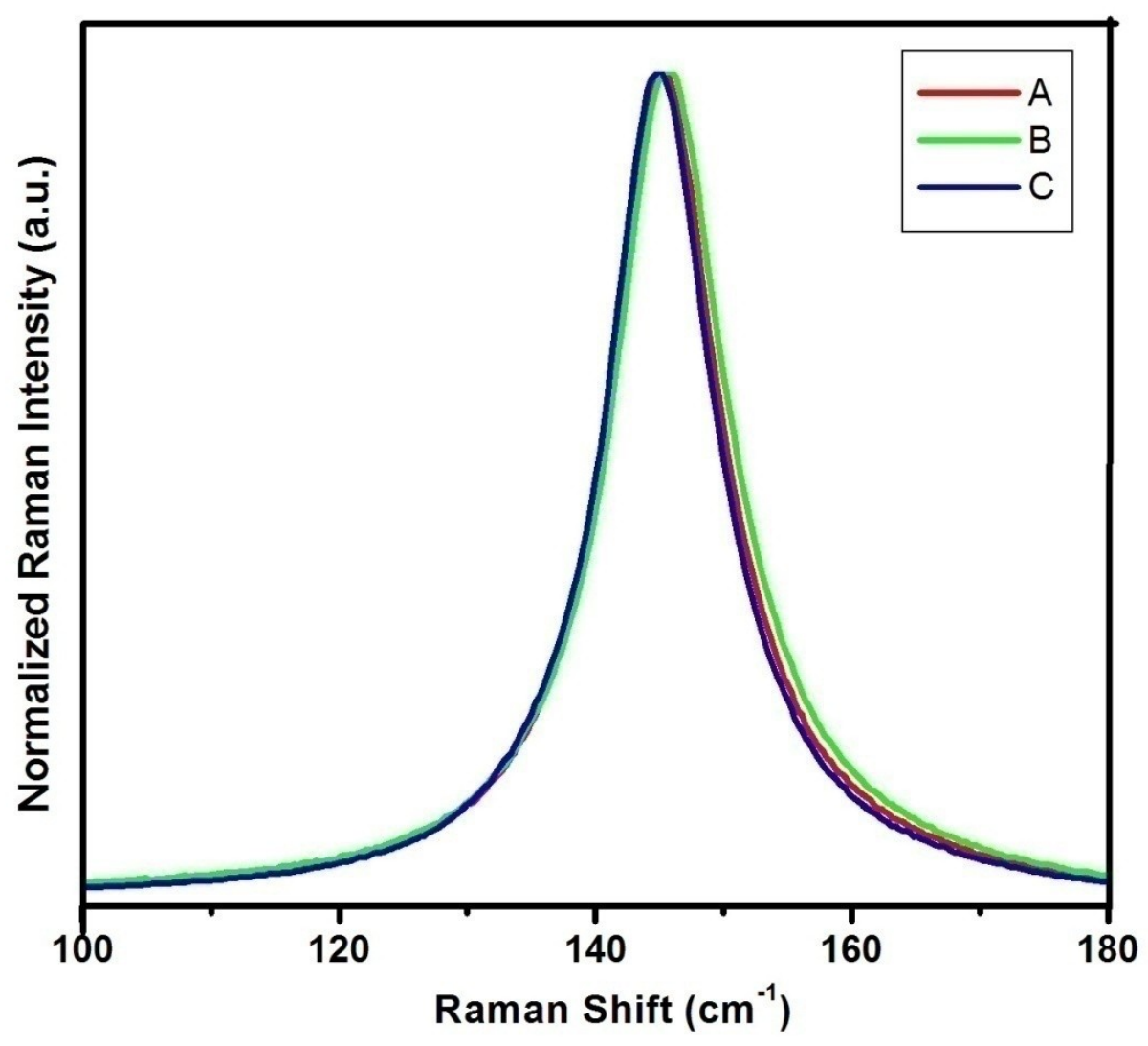

Fig.7. Normalized experimental Raman spectra of $144 \mathrm{~cm}^{-1}$ mode for prepared dual morphology $\mathrm{TiO}_{2}$ powders. 


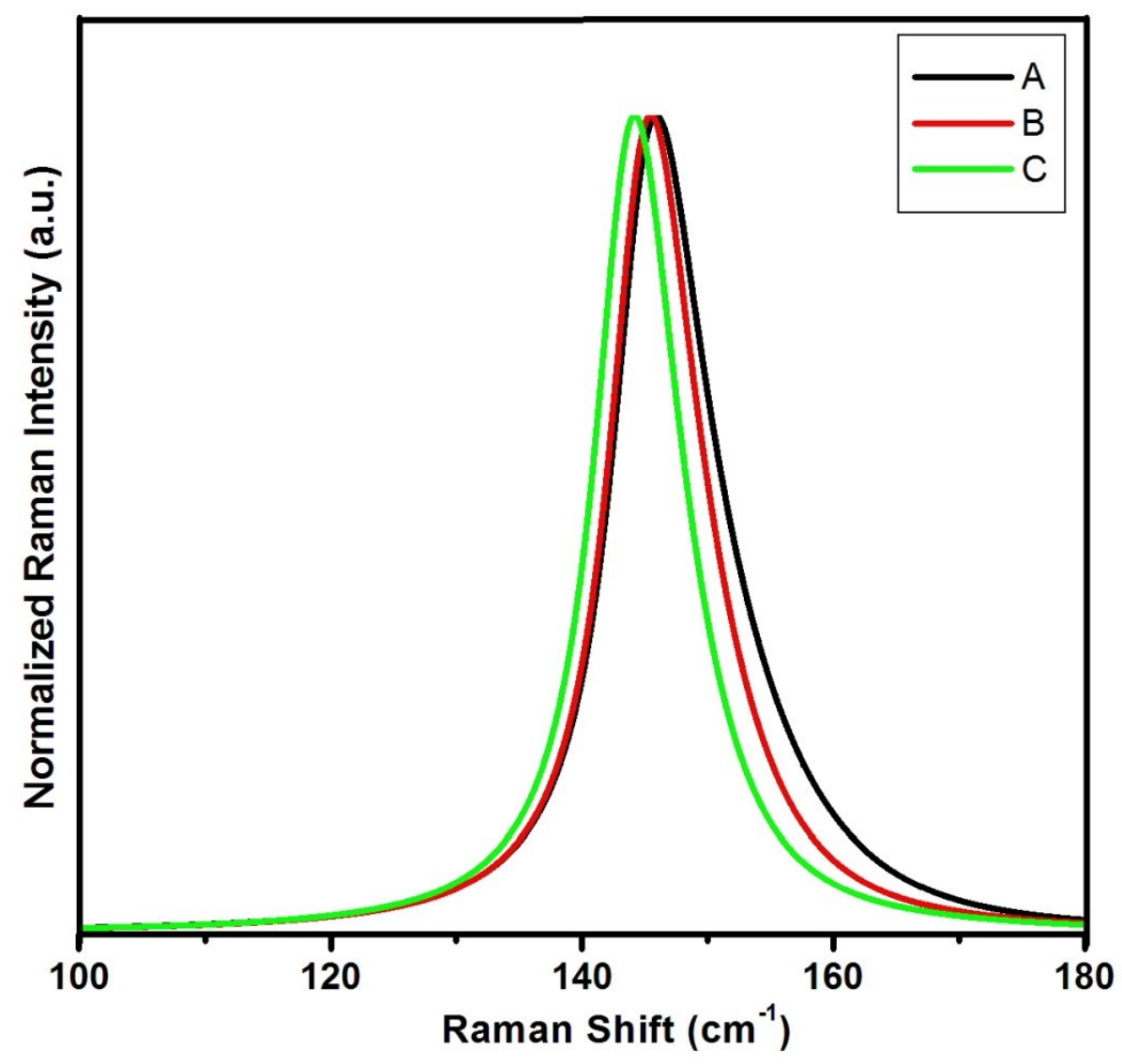

Fig. 8. Simulated Raman Spectra using phonon confinment model as a function of particle sizes at $144 \mathrm{~cm}^{-1}$ mode. 

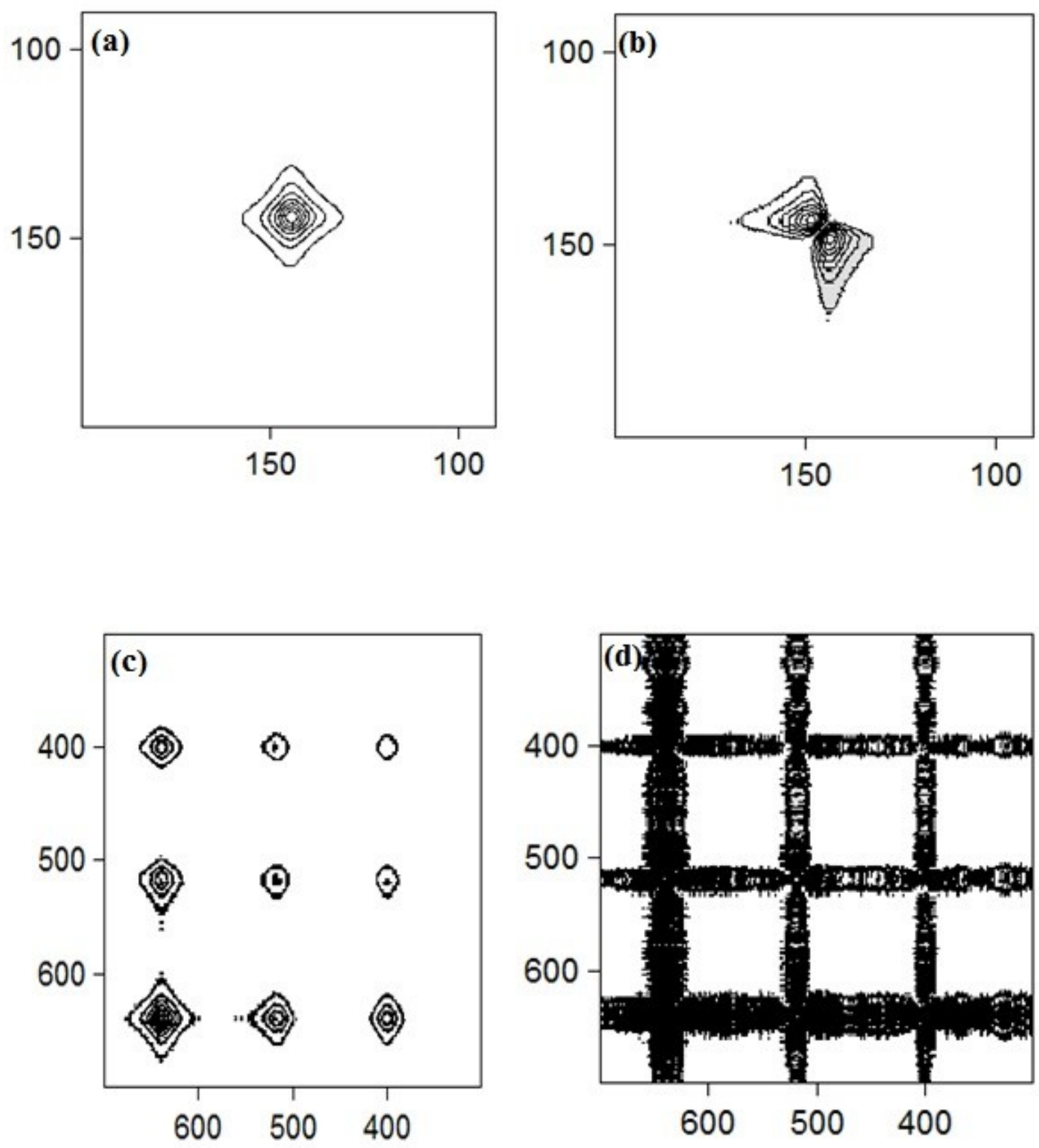

Fig. 9. (a) synchronous, (b) asynchronous 2D correlation spectra in the spectral range of $90-190 \mathrm{~cm}^{-1}$ and (c) synchronous, (d) asynchronous 2D correlation spectra in the region of $300-700 \mathrm{~cm}^{-1}$. 


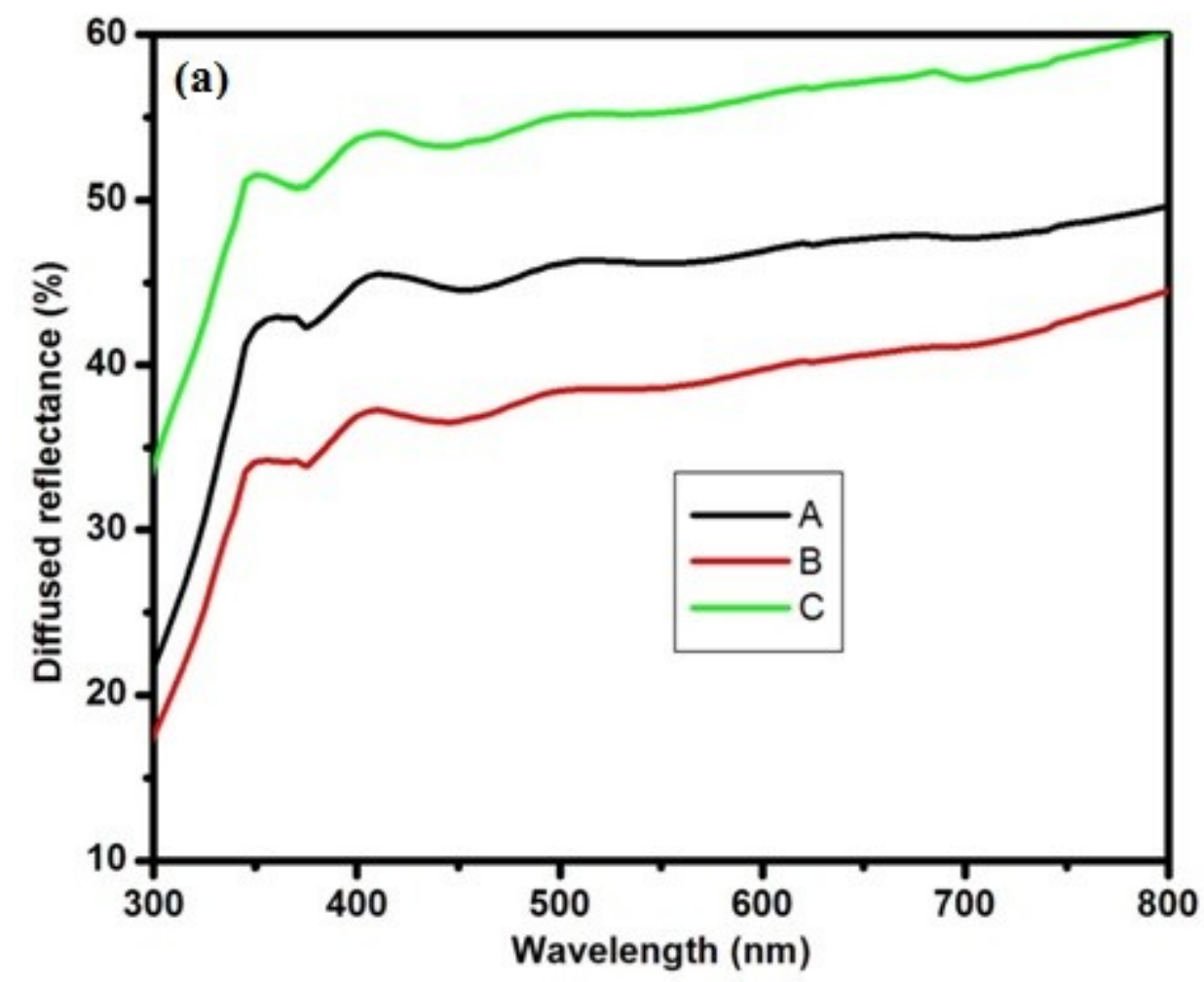

Fig. 10. Diffused reflectance spectra of of photoanodes before dye loading.

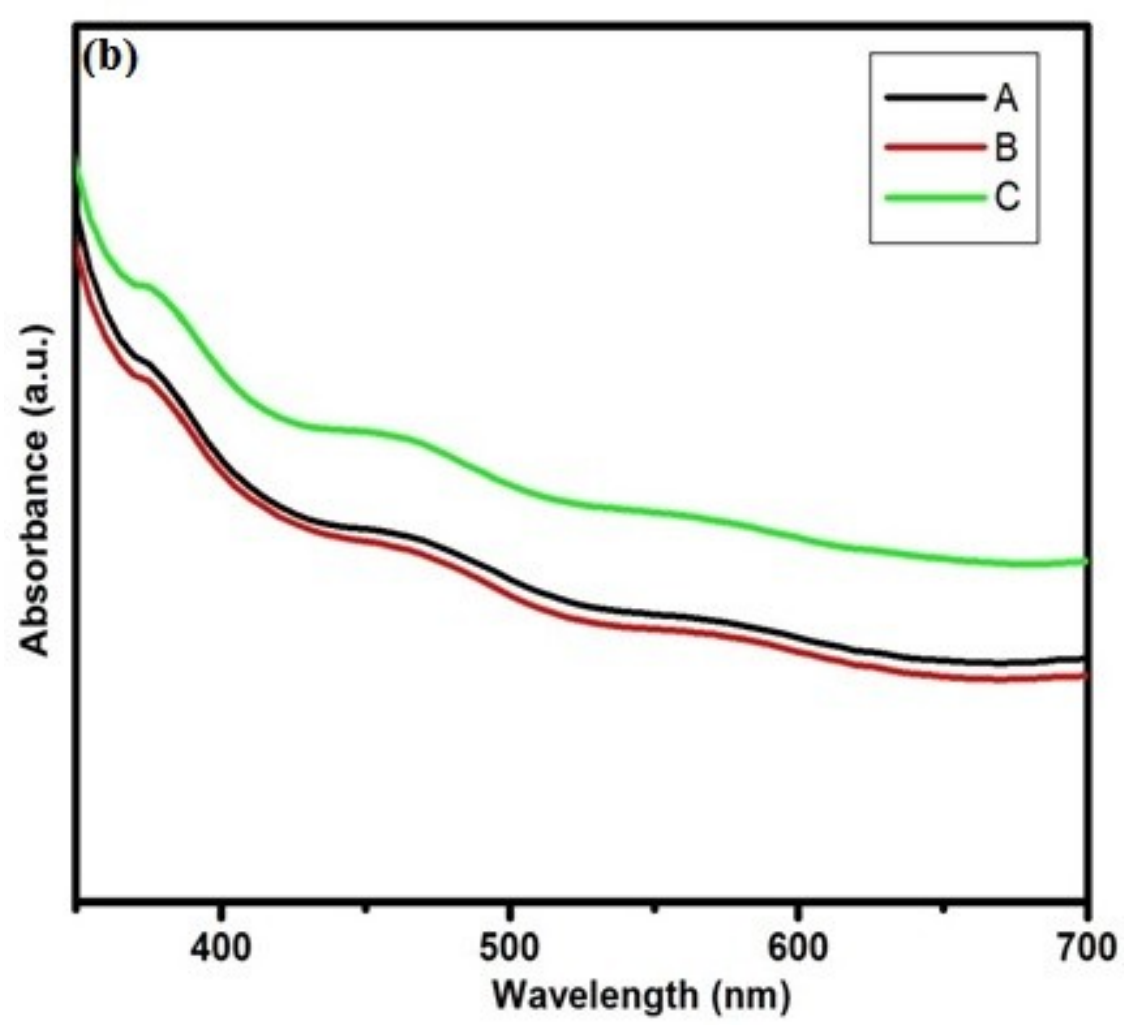

Fig. 11. Absorbance spectra of A, B and C photoanodes after the dye uptaking process. 


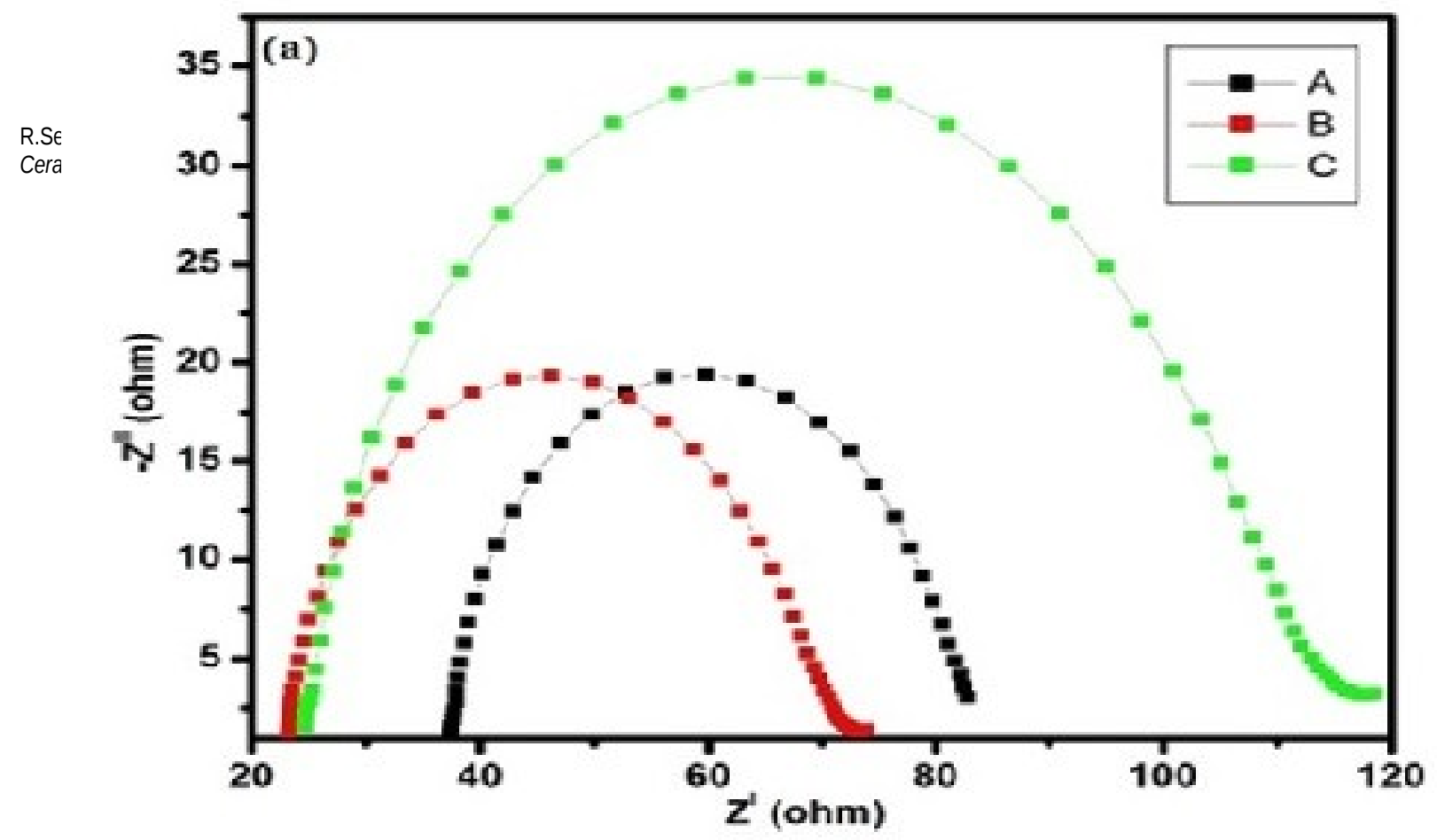

(b)

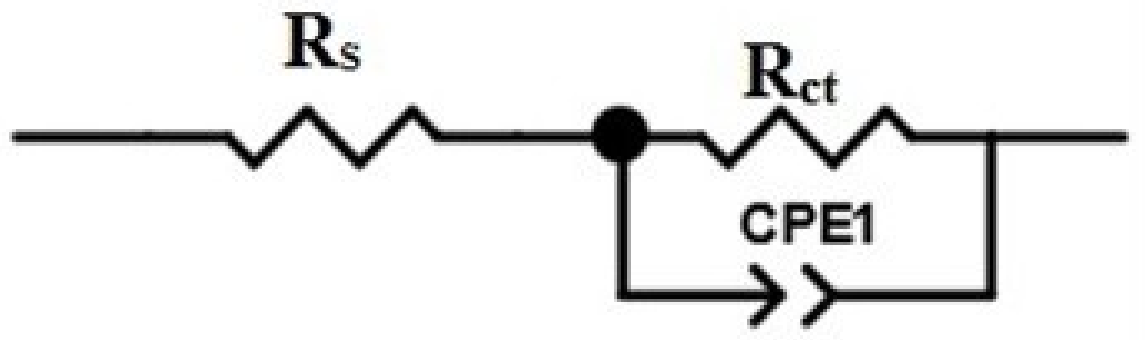



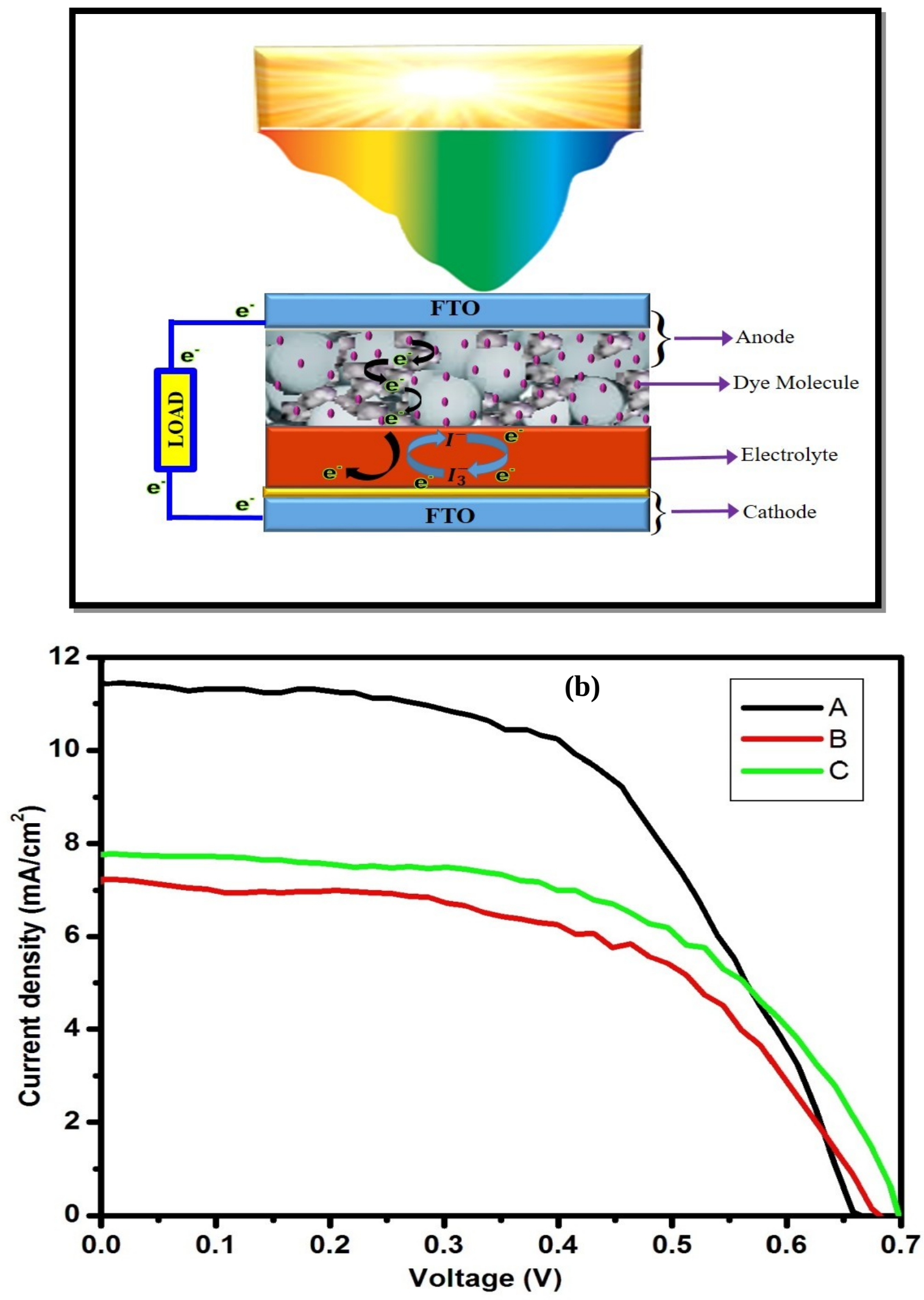

Fig.12.(a) Schematic device configuration and working mechanism of dye sensitized solar (c) cell. (b) Current density-Voltage curve for different photoanodes.

Fig. 13. (a). Nyquist plot representation of DSSCs based on A, B and C photoanodes under dark conditions, (b) Equivalent curcuit model of fabricated DSSC. 
Table 1. Angle of diffraction corresponding lattice planes of standard and calculated d-spacing values of Sample A.

\begin{tabular}{lllll}
\hline $2 \theta$ & $(\mathrm{hkl})$ & $\mathrm{d}_{\text {std. }}(\AA)$ & $\mathrm{d}_{\text {cal. }}(\AA)$ & $\Delta \mathrm{d}(\AA)$ \\
\hline 25.35 & $(101)$ & 3.509 & 3.516 & 0.007 \\
38.64 & $(112)$ & 2.328 & 2.331 & 0.003 \\
48.14 & $(200)$ & 1.888 & 1.892 & 0.004 \\
53.97 & $(105)$ & 1.697 & 1.699 & 0.002 \\
55.18 & $(211)$ & 1.663 & 1.666 & 0.003 \\
62.81 & $(204)$ & 1.478 & 1.480 & 0.002 \\
68.87 & $(116)$ & 1.362 & 1.363 & 0.001 \\
70.45 & $(220)$ & 1.335 & 1.337 & 0.002 \\
70.20 & $(215)$ & 1.262 & 1.264 & 0.002 \\
\hline
\end{tabular}

Table 2.The standard and calculated lattice parameters a, c and corresponding crystalline size of all the $\mathrm{TiO}_{2}$ materials.

\begin{tabular}{|c|c|c|c|c|c|}
\hline \multirow[t]{2}{*}{ Samples } & \multirow[t]{2}{*}{$\begin{array}{l}\text { Crystalline } \\
\text { Size (nm) }\end{array}$} & \multicolumn{2}{|c|}{$\begin{array}{c}\text { Lattice parameters } \\
\text { (standard) } \\
(\AA)\end{array}$} & \multicolumn{2}{|c|}{$\begin{array}{c}\text { Lattice parameters } \\
\text { (observed) } \\
(\AA)\end{array}$} \\
\hline & & $\mathrm{a}$ & $\mathrm{C}$ & A & $\mathrm{C}$ \\
\hline A & 12.21 & 3.777 & 9.501 & 3.765 & 9.411 \\
\hline B & 12.95 & & & 3.769 & 9.449 \\
\hline $\mathrm{C}$ & 16.10 & & & 3.771 & 9.481 \\
\hline
\end{tabular}

Table. 3. Photovoltaic and EIS Parameters derived from fabricated DSSC devices.

\begin{tabular}{lcccccc}
\hline Sample & $\begin{array}{c}\mathrm{J}_{\mathrm{SC}} \\
\left(\mathrm{mA} / \mathrm{cm}^{2}\right)\end{array}$ & $\begin{array}{c}\mathrm{V}_{\mathrm{OC}} \\
(\mathrm{V})\end{array}$ & $\mathrm{FF}$ & $\begin{array}{c}\eta \\
(\%)\end{array}$ & $\begin{array}{c}\mathrm{R}_{\mathrm{S}} \\
(\Omega)\end{array}$ & $\begin{array}{c}\mathrm{R}_{\mathrm{CT}} \\
(\Omega)\end{array}$ \\
\hline $\mathrm{A}$ & 11.49 & 0.66 & 0.54 & 4.17 & 37.0 & 45.4
\end{tabular}


R.Selvapriya, J.Mayandi, V.Ragavendran, V.Sasirekha,J.Vinodhini, J.M.Pearce. Dual Morphology Titanium Dioxide for Dye Sensitized Solar Cells. Ceramics International 45(6),7268-7277 (2019). https://doi.org/10.1016/j.ceramint.2019.01.008

\begin{tabular}{lllllll} 
B & 7.24 & 0.68 & 0.53 & 2.64 & 24.2 & 87.0 \\
C & 7.78 & 0.69 & 0.55 & 3.04 & 36.0 & 46.0 \\
\hline
\end{tabular}

